\title{
OPERAÇÕES RÍTMICAS E O PAPEL DA INFORMAÇÃO MORFOLÓGICA: O CASO TIKUNA (TICUNA)*
}

\author{
RHYTHMIC OPERATIONS AND THE ROLE OF MORPHOLOGICAL INFORMATION: \\ THE TIKUNA (TICUNA) CASE
}

\author{
Marília Facó Soares**
}

\section{RESUMO}

Retomando hipótese apresentada em Soares (1992) e explorada em Soares (1999), o presente artigo verifica o grau de participação da informação morfológica na construção do ritmo em Tikuna, língua tonal usada por um grande número de falantes distribuídos por uma área extensa da Amazônia, na América do Sul. Particularmente, verifica-se a existência ou não de um ritmo morfológico na língua e o lugar que nele ocupariam as raízes - entendidas como elementos indecomponíveis e, portanto, diferentes dos radicais (concebidos como resultados de raízes já categorizadas, seja por um morfema fonologicamente nulo, seja por um afixo aberto). Entre as conclusões mais importantes está a de se ter a possibilidade de dispensar a referência à margem direita da palavra como fator prosódico primeiro para o desencadeamento da constituição de pés métricos binários em Tikuna. Tal dispensa é possível quer em casos de sufixação, quer em casos de composição. Na sufixação, tem-se como possível o aparecimento do acento rítmico alimentado por uma espécie de colaboração, do ponto de vista perceptual, entre duração e altura da voz - colaboração essa que depende de uma camada tonal completamente especificada e que abre campo para operações rítmicas de nível mais baixo. $\mathrm{Na}$ composição, inexiste interação perceptual da altura da voz com a estrutura métrica, havendo indicações de que as operações rítmicas são aí diferentes daquelas de nível mais baixo. No que diz respeito à relação entre constituição morfológica e construção da grade métrica, observou-se, durante a sufixação, que a própria subdivisão do espaço rítmico duracional é coincidente com a de um pé métrico no plano acentual, tendo-se constatado que tal subdivisão acompanha de perto a estruturação morfológica interna à palavra, sendo que o mesmo se dá em casos de composição.

PALAVRAS-CHAVE: fonologia; morfologia; ritmo; Tikuna; Ticuna; línguas amazônicas

\begin{abstract}
Addressing the hypothesis presented in Soares (1992) and later explored in Soares (1999), this article examines the role of morphological information in the construction of rhythm in Tikuna (Ticuna), a tonal language used by a great number of speakers spread over a large area in Amazônia, in South America. In particular, it discusses if there is, or not, a morphological rhythm in the language and how the roots are placed within it - roots which are seen as undeployable, thus different from the radicals (conceived as results of previously categorized roots, either by a phonologically null morpheme, or by
\end{abstract}

\footnotetext{
* Este trabalho constitui uma parte daquele apresentado no Simpósio "Lenguas indígenas de América: estudios descriptivostipológicos y sus contribuciones para la linguística teórica” (Simpósio 611, 54 ICA, Viena, julho de 2012). A outra parte, voltada para a música tradicional Tikuna e comprobatória de aspectos rítmicos por meio dos quais a língua Tikuna se materializa e que são aqui abordados, passou a integrar artigo específico, destinado exclusivamente à música.

*** Museu Nacional/UFRJ - CNPq. Contato: marilia@acd.ufrj.br.
}

Rio de Janeiro | Volume 16 | Número Especial Comemorativo | p. 280-315 | nov. 2020 Celebrando mais de 50 anos do Programa de Pós-Graduação em Linguística da UFRJ e do percurso da Professora Emérita Miriam Lemle 
an overt affix). Among the most important conclusions is the possibility of dismissing reference to the right margin of the word as being the first prosodic factor in triggering the appearance of binary metric feet in Tikuna. The dismissal is possible both for cases of suffixation, as for those of composition. In suffixation, the appearance of rhythmic stress is possible fostered by some sort of collaboration, from a perceptual point of view, between length/ duration and voice pitch. This collaboration depends on a thoroughly specified tonal layer, which allows for rhythmic operations of a lower level. In composition, there is no perceptual interaction of voice pitch and metrical structure, and there are signs showing that the rhythmic operations here are different from those of a lower level. As to the relationship between morphological constitution and construction of the metric grid, it was noted that, during suffixation, the very subdivision of the durational rhythmic space is coincident with that of one metric foot in stress. It was found that such subdivision closely follows the internal morphological structuring of the word, and the same occurs in the cases of composition.

Keywords: phonology; morphology; rhythm; Tikuna; Ticuna; Amazonian languages.

\section{INTRODUÇÃO}

Soares (1992) ${ }^{1}$ apresentou e defendeu a seguinte hipótese sobre a liberdade do ritmo face à sintaxe: Quanto mais baixa a linha métrica, mais independente é o ritmo em relação à sintaxe. Em outras palavras, o grau de liberdade aqui está relacionado ao nível da linha métrica em que atuam processos referentes ao acento. Prenunciada em um trabalho anterior (Soares, 1991), essa hipótese foi explorada e confirmada em Soares (1999a).

No presente artigo, a mesma hipótese é retomada à luz da informação morfológica, que, embora presente nos trabalhos anteriores, é aqui especialmente focalizada com vistas à verificação do seu grau de participação na construção do ritmo em Tikuna, uma língua tonal usada por um grande número de falantes distribuídos por uma área extensa da Amazônia que abarca, na América do Sul, três países: Brasil, Peru e Colômbia ${ }^{2}$. Particularmente, verifica-se a existência ou não de um ritmo morfológico na língua e o lugar que nele ocupariam as raízes entendidas como elementos indecomponíveis e, portanto, diferentes dos radicais (concebidos como resultados de raízes já categorizadas, seja por um morfema fonologicamente nulo, seja por um afixo aberto $)^{3}$. De um lado, uma tal verificação torna-se importante como meio de coligir evidências para investigações em andamento sobre complexidade morfológica e seus efeitos sobre o ritmo. De outro lado, a verificação da interação entre ritmo e morfologia pode servir a estudos referentes à derivação de palavras morfologicamente complexas: na medida em que se admite a influência da estrutura morfológica sobre a pronúncia de palavras complexas ${ }^{4}$, o formato fonético dessas últimas pode fornecer pistas para o tratamento e as opções teóricas relativamente à própria complexidade morfológica, além de poder representar 
uma contribuição a estudos sobre mudança linguística. Ao lado da questão morfológica, o fato de o Tikuna ser uma língua tonal torna-a também especialmente interessante para uma investigação da convivência entre regras métricas (ligadas ao ritmo) e processos relativos à camada tonal - um interesse que pode se estender a todas as línguas tonais, de modo geral, e, ainda, a línguas de acento de altura (pitch accent languages).

Este artigo encontra-se organizado em três seções maiores. Na primeira seção, trazemos algumas considerações teóricas necessárias à abordagem do ritmo nas línguas naturais, lidando com conceitos, categorias e operações. Nela também colocamos em cena não só considerações sobre o pé métrico e demais categorias prosódicas, além da noção de colisão acentual mínima, mas também o modo de atribuição de proeminência relativa no nível frasal, destacando determinadas línguas que, como o Tikuna, apresentam operações vinculadas ao pé métrico no âmbito frasal. E dedicamos um espaço ao ritmo morfológico - um tema imprescindível em estudos sobre o ritmo. Na segunda seção, trazemos fatos do Tikuna, revisitando o ritmo no nível da palavra - o que nos leva a focalizar o acento propriamente linguístico, o acento rítmico, a colaboração entre duração e altura da voz (pitch) e o modo como o ritmo pode ser construído quando estão em jogo raízes, sufixos e, em especial, casos de composição. Nessa mesma seção, assumindo uma análise nitidamente composicional, assumimos a posição de Marantz (2002), segundo a qual a derivação de palavras se dá por fases, havendo linearização a cada anexação de morfema categorizador a uma estrutura. Assim, na construção das palavras focalizadas, prevemos o momento de negociação com a fonologia durante a construção da palavra, o que significa lidar com as operações sintáticas e morfológicas teoricamente previstas nessa construção e, além disso, com informações fonológicas relativas à camada tonal e com aquelas relativas à grade métrica. Ainda nessa mesma seção, colocamos de lado a margem direita como prosodicamente determinante para a construção do ritmo no âmbito da palavra em Tikuna, reafirmando, porém, o papel do pé métrico e a diferença, estabelecida em Soares (1999a), entre níveis de atuação de operações rítmicas (nível mais baixo ou não). Na terceira e última seção, apresentamos nossas conclusões.

\section{1- ALGUMAS CONSIDERAÇÕES TEÓRICAS PARA A ABORDAGEM DO RITMO}

1.1-O pé métrico e operações rítmicas no nível frasal

O pé métrico é uma categoria prosódica fundamental. Pode ser constituído de sílabas ou moras, sendo o seu núcleo assinalado, na literatura relativamente mais recente, por um x ou 
asterisco ${ }^{5}$. Pode também estar sujeito ou não a limites em termos de fronteiras ou, dito de outro modo, pode pertencer ou não a um sistema que não coloque limites em termos da distância entre acentos ou entre acento e fronteira de palavra ${ }^{6}$. No caso de ser o pé delimitado, esse possui um formato pleno, canônico, sendo também admitido, mediante condição, sob um formato mínimo, logicamente possível.

Em seu formato pleno, na visão de Hayes (1995), o pé delimitado possui núcleo localizado em sua margem esquerda ou direita e um lado dominado (coincidente com uma sílaba ou uma mora). Sua constituição interna está estreitamente ligada à existência ou não de sensibilidade à quantidade nas línguas que sejam objeto de análise. Em uma língua insensível à quantidade, o pé é constituído de sílabas e, ao apresentar núcleo em sua margem esquerda, é identificado como troqueu silábico, conforme Hayes $(1995)^{7}$. Já em uma língua sensível à quantidade, sob a ótica do mesmo autor, os pés métricos serão constituídos de moras, podendo ter seu núcleo localizado em sua margem esquerda ou direita e, ainda, mais de uma possibilidade de representação a partir de suas manifestações. Pés assim constituídos são identificados como troqueus moraicos ou iambos moraicos. Troqueus moraicos apresentam núcleo em sua margem esquerda. Nesse caso, sua representação pode comportar, internamente, duas moras correspondentes a duas durações breves, sendo que sobre a mora à esquerda encontra-se localizado o núcleo do pé. Como segunda possibilidade, o troqueu moraico pode comportar uma única duração longa que, sendo a materialização de duas moras, constitui propriamente o lugar em que se situa o núcleo - o que exclui a existência, nessa possibilidade, de um lado dominado do pé em que haveria, seguindo-se à duração longa do núcleo, uma outra mora materializada por duração breve. ${ }^{8}$ Quanto a iambos moraicos, esses são pés com núcleo localizado em sua margem direita; e também apresentam mais de uma possibilidade de representação a partir de suas manifestações. Uma primeira possibilidade é ter-se o núcleo à direita como passível de vínculo a uma ou duas moras, sendo que o lado dominado do pé, que precede o núcleo, está sempre vinculado a uma única mora, correspondente a uma duração breve. A ambiguidade moraica do núcleo cria aqui a possibilidade para que sejam acolhidos dois tipos de iambo moraico: o iambo balanceado (em que as duas moras correspondem a duas durações breves, manifestadas, respectivamente pelo lado dominado e pelo núcleo do pé); e o iambo desbalanceado (em que à mora do lado dominado seguem-se as duas moras comportadas por um núcleo longo). Uma outra possibilidade para o iambo moraico está em se ter o pé coincidente com o próprio núcleo, por sua vez circunscrito a duas moras (núcleo longo), sendo que nessa configuração não há lado dominado do pé. ${ }^{9}$ Como consequência, surge aqui um ponto de sobreposição entre o iambo moraico e o troqueu moraico (sobreposição parcial). 
Sob um formato mínimo logicamente possível, o pé pode ser identificado como degenerado, se observada determinada condição. Em uma formulação preliminar, esse tipo de pé chegou a ser concebido, na visão de Hayes (1995), como constituído de uma única sílaba ou uma única sílaba breve, com um lugar aparentemente previsto, respectivamente, em sistemas insensíveis ou sensíveis à quantidade. Em uma formulação final, porém, na visão do mesmo autor, um pé identificado como degenerado é constituído apenas de uma sílaba breve, mesmo em sistemas sem distinções de quantidade ${ }^{10}$. A consequência dessa formulação é que se assume serem as línguas sem distinção de quantidade possuidoras somente de sílabas breves. Vale registrar que a existência de pés degenerados, nas línguas que os admitem, somente se dá mediante licenciamento: a marca acentual do pé em causa deve ser dominada por uma outra marca acentual (isto é, na mesma coluna métrica, deve haver uma marca acentual de nível mais alto do que aquele do pé em causa). Isso nos leva diretamente à grade métrica, que é um modo de representação gráfica do ritmo linguístico, e ao papel do pé enquanto constituinte métrico.

Como modo de representação gráfica do ritmo linguístico, a grade métrica tem experimentado, nas últimas décadas, dois grandes tipos de representação: a) a grade métrica parentetizada, que exibe parênteses em suas camadas ou linhas, indicando claramente os constituintes que a integram em cada camada/linha; b) a grade métrica que, sem indicar constituintes internos, exibe apenas peridiocidades rítmicas, tendo-se tornado conhecida como representação só-grade. Selkirk (1986), Halle e Vergnaud (1987), Hayes (1995), Idsardi (1992), Halle e Idsardi (1995) são exemplos de autores que, guardadas as devidas diferenças entre os modelos teóricos assumidos ${ }^{11}$, trabalharam com a grade métrica parentetizada. Prince (1983), Selkirk (1984), Nespor e Vogel (1989), Nespor (1990) estão entre aqueles que, com abordagens diferentes $^{12}$, optaram pela representação só-grade. A grade métrica parentetizada permite a visualização imediata da força diferenciada de seus constituintes que, por sua vez, são diferentes devido ao seu próprio lugar em uma hierarquia. Já uma representação só-grade está indiretamente relacionada a constituintes, podendo recuperar informação prosódica sobre esses últimos quer pela adoção do princípio do ciclo em um alinhamento texto-grade (Selkirk, 1984: 53-56), quer pela admissão de um momento anterior a operações puramente rítmicas, que modificariam eufonicamente a própria grade (Nespor e Vogel 1989: 71).

No que diz respeito ao pé métrico, seu papel e sua definição encontram-se interligados. O pé se define como o menor constituinte métrico. Por ser a unidade métrica de nível mais baixo, é a referência inicial para a estruturação do ritmo, ligando-se a questões importantes para essa estruturação, como a distância prosódica mínima entre os próprios pés, a relação entre pés 
métricos e demais categorias prosódicas, a definição de colisão acentual mínima e a estruturação do ritmo em nível frasal.

No que diz respeito à distância prosódica mínima entre pés, essa é uma questão nascida da necessidade teórica de se lidar com pés ternários, dificilmente aceitos como pés básicos por diferentes autores ${ }^{13}$. Uma maneira de lidar com as alternâncias ternárias (e eliminá-las) é tratálas como resultantes da construção de pés binários não-adjacentes, ou seja, com a interveniência de apenas uma duração breve saltada entre os pés - o que é conhecido, na literatura sobre teoria métrica, como análise local fraca. Essa é a solução adotada por Hayes $(1995)^{14}$, que vê a análise local fraca como um parâmetro. Já a adjacência imposta a pés binários decorre do que se chama de análise local forte. ${ }^{15}$ É importante notar que, mesmo em uma língua que forneça evidências para adoção da análise local fraca, essa somente pode ser aplicada aos dados se a janela de análise incluir pelo menos duas sílabas breves, para que uma dessas possa ser saltada. Ou seja, mesmo em línguas que podem ser tratadas via análise local fraca, essa análise só se dá onde é possível ${ }^{16}$. Com referência ao tipo de língua na qual a análise local fraca é admissível, os casos abordados por Hayes (1995) mostram que, entre as línguas que exibem análise local fraca, encontram-se tanto línguas que contam moras (sensíveis à quantidade) quanto aquelas que computam sílabas (insensíveis à quantidade). Ao que tudo indica, as línguas insensíveis à quantidade para as quais se propôs também uma análise local fraca revelam um ponto de contato com os sistemas que são sensíveis à quantidade, na medida em que exibem não só durações materializadas foneticamente, mas também revelam pontos de ambiguidade entre um sistema e outro $^{17}$.

Sendo uma categoria prosódica fundamental e o menor constituinte métrico, passível de submissão a uma distância prosódica mínima, o pé é a unidade que está na base de categorias prosódicas de nível mais alto, como a palavra prosódica (ou fonológica), o grupo clítico, a frase fonológica (ou sintagma fonológico), a frase (ou sintagma) entoacional. A importância do pé métrico pode ser visualizada sob diferentes ângulos, entre esses estando a possibilidade de sua utilização para a definição de colisão mínima e para a estruturação do ritmo em nível frasal, além, é claro, da estruturação em níveis métricos mais baixos do que a frase fonológica, como o grupo clítico ${ }^{18}$ e a palavra prosódica.

No que diz respeito à colisão acentual mínima, há línguas, como o inglês e o catalão, que definem esse tipo de colisão na terceira linha métrica (nível da palavra prosódica). Há, porém, línguas em que a colisão acentual mínima se define na segunda linha métrica (nível do pé) - caso, por exemplo, do grego ${ }^{19}$. Em ambas as situações, não se tem a interveniência de elementos ${ }^{20}$ mais fracos em qualquer nível métrico abaixo daquele em que a colisão mínima é 
definida. Ambos os tipos de situação encontram-se esquematizados, respectivamente, em (1a) e (1b) abaixo ${ }^{21}$, que exibem representações de grade métrica ${ }^{22}$ e de categorias prosódicas hierarquizadas, colocadas lado a lado por razões expositivas ${ }^{23}$. Nosso foco, em (1a) e (1b), está nas periodicidades rítmicas e na noção de colisão acentual propriamente dita. Mais adiante, neste artigo, a representação do tipo só-grade, como as que se encontram em (1), nos será útil para a visualização da proximidade ou não entre o pé métrico e fronteiras devidas à estruturação morfológica.

(1a) Colisão mínima acentual mínima no âmbito da palavra prosódica

\begin{tabular}{|c|c|}
\hline $\begin{array}{ll} & * \text { linha } 4 \\
* & * \text { linha } 3 \\
* & * \text { linha } 2 \\
* & * \text { linha } 1\end{array}$ & $\begin{array}{l}\text { frase fonológica }(\varphi) \\
\text { palavra prosódica }(\omega) \\
\text { pé }(\Sigma) \\
\text { sílaba }(\sigma)\end{array}$ \\
\hline $\mathrm{p} \quad \mathrm{P}$ & \\
\hline
\end{tabular}

(1b) Colisão mínima acentual mínima no âmbito do pé métrico

\begin{tabular}{|lll|}
\hline & $(*)^{24}$ & linha 3 \\
$*$ & $*$ & linha 2 \\
$*$ & $*$ & linha 1 \\
$\mathrm{p}$ & $\mathrm{p}$ & \\
\hline
\end{tabular}

Nas duas situações esquematizadas em (1a) e (1b), as línguas tenderão a desfazer a colisão acentual ${ }^{25}$.

Assim como o pé métrico é um constituinte potencialmente colocado à disposição para a definição de colisão acentual mínima (o que, de fato, é materializado em algumas línguas), o mesmo se dá em termos de sua potencialidade para utilização no domínio frasal.

No momento da atribuição de proeminência relativa no nível frasal, uma situação possível é aquela em que uma tal atribuição seja precedida por estágios em que a estrutura métrica já tenha sido atribuída a todas as sílabas (ou moras) até o nível da palavra prosódica ${ }^{26}$. Em outros termos, nessa situação, o acento frasal levaria em conta sequências de palavras e, de alguma forma, seus limites, antes de subordinar, ritmicamente, pela via do acento, determinada(s) palavra(s) a uma outra. Essa é a situação, por exemplo, do inglês moderno. Há, porém, uma outra situação possível, consubstanciada por línguas em que padrões acentuais são levados para o nível frasal, isto é, por línguas em que as alternâncias acentuais vinculáveis ao pé métrico se dão sem respeito a fronteiras de palavras. Estão nesse caso, por exemplo, línguas indígenas não aparentadas, como o Cayuvava ${ }^{27}$, o Yawelmani ${ }^{28}$, o Tikuna ${ }^{29}$, além de línguas não-indígenas, como o sueco ${ }^{30}$ e o hebreu moderno ${ }^{31}$, entre outras. 


\section{2-Do ritmo morfológico}

Hayes (1995) considera que os sistemas acentuais se dividem em dois tipos de variedade: a rítmica e a morfológica. ${ }^{32} \mathrm{Na}$ variedade rítmica, o acento tem por base, segundo esse autor, fatores puramente fonológicos, como o peso silábico, as limitações de distância quer entre acentos, quer entre acento e fronteiras de palavra. Já na variedade morfológica, o acento serve à elucidação da estrutura morfológica de uma palavra, sem que estejam descartados aspectos de interação com a variedade rítmica. A seguir, no Quadro 1, reunimos alguns casos documentados da variedade morfológica.

Quadro 1 - Atribuição do acento em interação com a morfologia

\begin{tabular}{|c|c|}
\hline \multirow{3}{*}{$\begin{array}{l}\text { Acento atribuído conforme as formas linguísticas em jogo na } \\
\text { palavra: } \\
\text { (a)participem da constituição do radical (stem) ou operem no } \\
\text { processo de sufixação; } \\
\text { (b)sejam raízes (roots) (com uma das sílabas vinculadas ao } \\
\text { acento principal de palavra) ou operem no processo de sufixação } \\
\text { e prefixação. }\end{array}$} & $\begin{array}{l}\text { Algumas línguas } \\
\text { exemplificadoras }\end{array}$ \\
\hline & Auca $^{33}$ \\
\hline & Cahuilla $^{34}$ \\
\hline $\begin{array}{l}\text { Atribuição do acento principal de palavra segundo diferentes } \\
\text { padrões em vários contextos morfológicos. }\end{array}$ & Cayuvava $^{35}$ \\
\hline $\begin{array}{l}\text { Alternância rítmica ternária aparente com padrão acentual } \\
\text { encontrado em circunstâncias morfológicas particulares }\end{array}$ & $\begin{array}{l}\text { Yupik - Pacífico } \\
\left(\text { Koniag }^{36}\right)\end{array}$ \\
\hline $\begin{array}{l}\text { Aplicação cíclica das regras de acento com base em um conjunto } \\
\text { de níveis morfológicos }\end{array}$ & $\begin{array}{l}\text { Choctaw, } \\
\text { Chickasaw } \\
\end{array}$ \\
\hline $\begin{array}{l}\text { Acento atribuído inclui exigência métrica sobre os radicais (que } \\
\text { devem ser minimamente constituídos por um pé). }\end{array}$ & Paamês ${ }^{38}$ \\
\hline $\begin{array}{l}\text { Existência de acento secundário idiossincrático portado ou } \\
\text { desencadeado por um conjunto de radicais (stems) e afixos; } \\
\text { existência de acento morfologicamente delimitado. }\end{array}$ & Estoniano $^{39}$ \\
\hline $\begin{array}{l}\text { Acento afetado pela morfologia, que possui papel na formação } \\
\text { de palavras fonológicas. }\end{array}$ & Fijiano $^{40}$ \\
\hline Sensibilidade parcial da morfologia ao sistema acent & Winnebago $^{41}$ \\
\hline
\end{tabular}

Os casos exemplificadores de manifestação da variedade morfológica mostrados no Quadro 1 reúnem aspectos da relação entre morfologia e padrões acentuais que convém ressaltar. Esses vão desde a importância da identificação de formas como raiz (root), radical (stem) e tipos de afixo e, ainda, de contextos ou circunstâncias morfológicas até a inclusão de exigências métricas e desencadeamento de acento secundário. Tais aspectos, que também comportam graus de afetação e sensibilidade do acento à morfologia, envolvem possibilidades que necessitam, além de explicitação, de delimitação quer em línguas específicas, quer no âmbito das línguas naturais como um todo. 


\section{2-FATOS DO TIKUNA: O RITMO NO NÍVEL DA PALAVRA}

\section{1-O acento linguístico}

No que diz respeito ao nível da palavra, o acento linguístico em Tikuna é manifestado por duração longa e é determinado por regra, sendo localizado na sílaba mais à esquerda de uma raiz. Em outros termos, concebido no âmbito de uma teoria da proeminência, o acento linguístico abstrato é previsível e sua duração materialmente longa constitui um detalhe fonético. Com relação às raízes em Tikuna, essas não possuem mais de três sílabas. De acordo com visão veiculada pela primeira vez em Soares (1992), isso faz com que o acento linguístico recaia no interior de um limite de três sílabas computado a partir da margem direita (isto é, para efeitos desse limite, a direção de contagem é da direita para a esquerda). Vejam-se os exemplos em $(2)^{42} 43$.

(2)

a.

$$
\text { tsa dza } \quad([\text { tsa }[\text { dza }]])
$$

1PS- criar-se, crescer

' $(\mathrm{Eu})$ me criei'

b.

$$
\mathrm{ni} \quad \tilde{\mathrm{i}} \quad\left(\left[\left[\begin{array}{ll}
\mathrm{ni}] & \tilde{\mathrm{i}}]
\end{array}\right)\right.\right.
$$

3PCL -'DAT'

'para ele; o'

c.

na $\quad$ g $\quad([$ [na $] \mathrm{gu}])$

3P -LOC

'dentro dele'

d.

$$
\begin{aligned}
& \text { ma?ı } \\
& \text { 'vida' } \\
& \text { ([ma?i]) }
\end{aligned}
$$

e.

$$
\begin{aligned}
& \text { tsa- tak@ ([tsa }[\text { taku] }]) \\
& \text { 1PS- sem mãe }
\end{aligned}
$$

'(Eu) fiquei sem mãe/ fiquei órfão' 
f. $\quad-\backsim v$

natici

'mas, então'

g.

doiłr

'pessoa'

h.

okळ?₹

'conselho'

i.

koniwa

' taxizeiro' (espécie de árvore)' ([natiri $])$

*

([duiræ ])

$*$

([ukuع ])

([koniwa)

É importante notar aqui que a localização do acento linguístico estabelece pontos de contato com a questão do estatuto prosódico de formas linguísticas, como prefixos verbais, clíticos sintáticos ${ }^{44}$ e bases pronominais a que se agregam sufixos, além do próprio estatuto da raiz, que é determinante para a atribuição do acento linguístico. Algumas dessas formas linguísticas se fazem presentes nos dados acima. Em (2a) e (2e), estão palavras morfologicamente constituídas de prefixo verbal e raiz e, em formas como essas, o prefixo, constituído de uma única sílaba, se manifesta foneticamente através de uma duração silábica breve. Essa é a situação comum nas formas verbais, o que é um indicativo de que, nessas formas, o prefixo se configura como sílaba átona que, agregada a uma raiz categorizada como verbal, participa de uma mesma palavra prosódica juntamente com essa última. Outra é a situação prosódica dos clíticos sintáticos, das bases pronominais a que se agregam sufixos. Com exemplos em (2b) e (2c), tem-se aí, foneticamente, uma duração longa sobre a sílaba coincidente com a marca de pessoa - o que, fonologicamente, em nossa análise, se traduz pela atribuição de um acento linguístico. Com isso, outro será o estatuto da marca de pessoa nessas formas. Prosodicamente, ao receberem acento próprio (manifestado por uma duração longa), não se confundem com os prefixos verbais. Do ponto de vista gramatical, também se diferenciam desses últimos, por poderem receber marcação de caso morfológico (caso dos clíticos sintáticos ${ }^{45}$ ) ou sufixos categorizadores (situação das bases pronominais ${ }^{46}$ ). Levando- 
se em conta que o formato fonético das formas linguísticas com algum grau de complexidade pode fornecer pistas para o tratamento de sua constituição interna, teríamos aí um bom elemento para confirmar a existência de uma raiz em (2b) e (2c) - o que significa dizer que também aí estariam exemplos de atribuição de acento linguístico conforme a mesma regra que vigora para as raízes presentes nas demais formas em (2).

No que diz respeito à relação entre formato prosódico e estatuto das raízes, a questão que se nos apresenta é a seguinte: a localização do acento linguístico sobre as raízes seria dependente da categorização dessas últimas? Em outras palavras, a formulação relativa à atribuição do acento linguístico em Tikuna teria como seu ponto de partida a raiz (root) ou o radical (stem)? Em busca de resposta a essa pergunta, verifiquemos se raízes em Tikuna são pronunciáveis como formas isoladas e se a presença de um afixo é determinante para a localização do acento linguístico durante a derivação de palavras ${ }^{47}$. Para tanto, consideremos alguns dados que compartilham a mesma raiz e se encontram a seguir ${ }^{48}$. Vejamos, primeiramente, aqueles em (3):
(3)a.
\# $^{-}$
aure
'dieta (raiz), 49
b. $\sim$ \# $^{\smile}$
tsa aure
1PS- fazer dieta
'(Eu) faço dieta'
c. \# $\quad$ u
aurer̃
'fazer dieta- NOMLZR'
'o ato de fazer dieta; dieta'
d. $\sim \#^{\sim} \sim$
ta aurer? ${ }^{50}$
$3 \mathrm{PF} / \mathrm{C}^{51}$-fazer dieta- NOMLZR
'o ato de ela fazer dieta'
([aure])

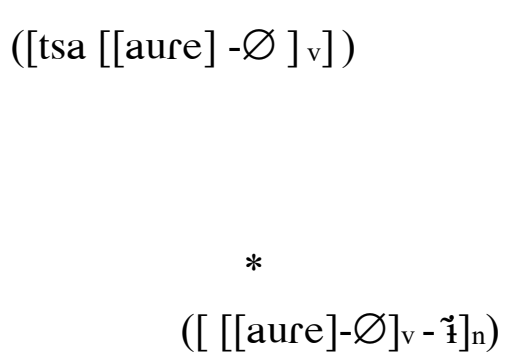

Rio de Janeiro | Volume 16 | Número Especial Comemorativo | p. 280-315 | nov. 2020 
Em (3a), a forma pronunciada de modo isolado e materialmente coincidente, na superfície, com a raiz referente a 'dieta' 52 não é a princípio nominal ou verbal, necessitando de um afixo categorizador. Em (3b), a mesma raiz integra uma forma considerada como verbal o que significa que a raiz deverá estar verbalizada. A nossa hipótese é de que a verbalização da raiz em dados como (3b) se faz através de um sufixo verbalizador fonologicamente nulo (que representa a categoria funcional $\mathrm{v}^{53}$ ), tal como se vê na representação mais abstrata que se encontra do lado direito em (3b). Quanto a (3c) e (3d), tem-se aí uma construção nominal, resultante de um processo de nominalização efetuado por um sufixo aberto (que materializa a categoria funcional $\left.\mathrm{n}^{54}\right)$. A nominalização pode se dar sobre a raiz verbalizada $(3 \mathrm{c})^{55}$ ou sobre uma forma verbal integrada por prefixo pessoal $(3 \mathrm{~d})^{56}$, sendo que os dados materialmente exibidos correspondem a estruturas cuja representação está, respectivamente, do lado direito em (3c) e (3d). Os dados em (3) fornecem evidências da existência, em Tikuna, de raízes categorialmente neutras, além de mostrar processos de categorização que decorrem de uma primeira concatenação entre raiz e afixo e de concatenações subsequentes entre uma base categorizada e um outro afixo (o que pode levar a uma recategorização). Tanto no caso da primeira categorização de uma raiz por efeito de sua concatenação com um primeiro afixo quanto em uma nova concatenação e consequente recategorização de uma base já categorizada, o acento linguístico inicialmente atribuído à sílaba mais à esquerda de uma raiz não se desloca, ou seja: concatenações não têm efeito sobre o acento atribuído à raiz - o que indica ser essa a fornecedora do formato prosódico para a atribuição do acento linguístico, independentemente de qualquer categorização.

Passemos aos dados em (4), que se diferenciam daqueles em (3) por apresentar uma raiz selecionadora de um argumento interno. Por hipótese, digamos que há, primeiramente, concatenação da raiz a esse argumento e, depois, a concatenação do afixo que terá o papel de categorizar a base então constituída.

$$
\begin{aligned}
& \text { a. \# } \\
& \text { pogi ([[po] [N-gi }]]) \\
& \text { pescar }^{57} \text {-PL } \\
& \text {...'pescar objeto plural [peixes]' } \\
& \text { b. } \sim \text { \# } \\
& \text { napogi } \\
& \text { 3P-pescar objeto plural [peixes] } \\
& \text { 'ele pesca/pescou peixes' }
\end{aligned}
$$

Rio de Janeiro | Volume 16 | Número Especial Comemorativo | p. 280-315 | nov. 2020 
c.

pogi?ł $([[[\operatorname{pogi\mathfrak {i}}]-\varnothing] \mathrm{v}-\tilde{\mathrm{i}}] \mathrm{n})$

pescar objeto plural [peixes]-NOMLZR

'pesca de objeto plural [peixes]'

No caso de (4a), a raiz referente a 'pescar' apresenta-se aumentada por um complemento, constituído por um nome $(\mathrm{N})$ subtendido acompanhado de sufixo indicador de plural - o que leva à interpretação 'pescar objeto plural [peixes]'. Essa "raiz aumentada"58, porém ainda não categorizada, pode alcançar um status verbal ou nominal: ao receber um sufixo fonologicamente nulo, torna-se um verbo (4b); ao integrar uma construção que passa por um processo de nominalização, o resultado é um nome. Se a raiz é selecionadora de um argumento interno, a hipótese de que deve haver concatenação da raiz com esse argumento, antes de sua concatenação com um feixe de traços (manifestado por um afixo) determinante para sua categorização, recebe um suporte do ponto de vista prosódico: o complemento pluralizado nos dados em (4) forma um pé métrico com a sílaba da raiz, em conformidade com a teoria da proeminência por nós adotada na análise da língua. Com relação à manutenção do acento linguístico, os dados em (4) apoiam conclusão já alcançada por meio dos dados em (3): o acento linguístico inicialmente atribuído à sílaba mais à esquerda de uma raiz não se desloca. Como concatenações não têm efeito sobre o acento atribuído à raiz e essa é a fornecedora do formato prosódico para a atribuição do acento linguístico, independentemente de qualquer categorização, podemos rever nossa afirmação anterior, constante do inicío desta seção. Ao invés de dizer que o acento linguístico recai na sílaba mais à esquerda de uma raiz, computandose um limite de três sílabas a partir da margem direita, diremos tão somente que o acento linguístico, em Tikuna, tem sua atribuição alinhada à margem esquerda de uma raiz. No que diz respeito à importância de se aliar a noção de pé métrico a essa descrição e à relevância prosódica propriamente dita da margem direita da palavra em Tikuna, esses são pontos que passam por outros elementos, focalizados a seguir.

\section{2- Acento e camada tonal. Do acento rítmico.}

Ao lado do acento linguístico, o Tikuna também possui um acento rítmico. Se uma raiz recebe sufixos, pode ocorrer de o acento de palavra não só coincidir com o acento da raiz, mas ser também o único acento manifesto no domínio da palavra, conforme visto em (4c), repetido aqui como (5) e com informações referentes à materialização da camada tonal ${ }^{59}$ : 
(5)

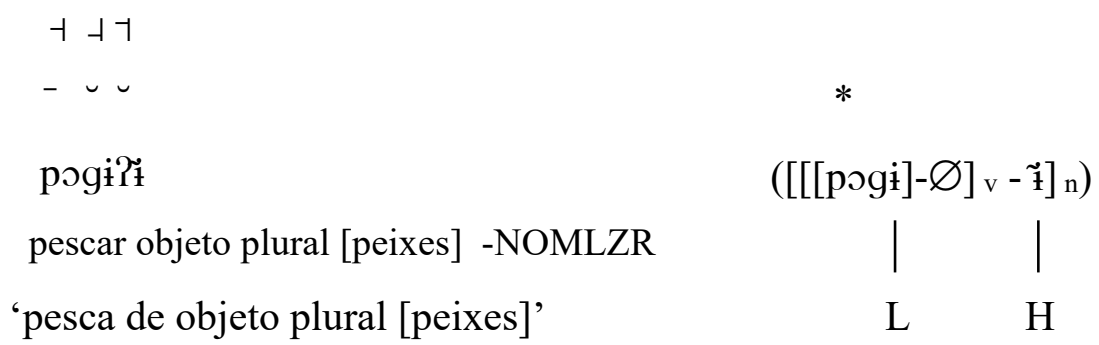

Entretanto, há exemplos como (6a) e (6b), que exibem acento linguístico afastado da margem direita da palavra para além de um limite de três sílabas:

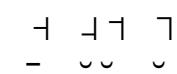

pogîłwa

$\left[\left[[[p o g i]-\varnothing]_{v}-\tilde{r}\right]_{n}\right.$ wa $]$

pescar-NOMLZR LOC 60

'na pesca/ no ato de pescar'

L $\quad \mathrm{H} \quad \mathrm{H}$

$(6 b)$

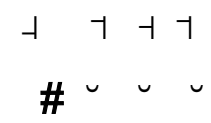

nõ $\mathrm{k}^{\mathrm{h}}$ utsima

[[[nuki $]$ itsi $] \mathrm{ma}]^{61}$

tempo-INTENS 1 -INTENS 2

'muitíssimo tempo'

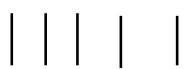

L H H L H

Em (6a) e (6b), a duração não é modificada. Esse fato é compensado por um uso rítmico da altura da voz (pitch) nas sílabas que constituem os sufixos. De fato, é possível encontrar situações em que se tem o aparecimento do acento rítmico alimentado por uma espécie de colaboração entre duração e altura da voz. Vejam-se, a propósito, os exemplos em (7a), (7b) e $(7 \mathrm{c})^{62}$.

$\begin{array}{cc}\dashv \dashv \dashv & * \\ -\lrcorner \iota & \text { [nukima] } \\ \text { nõk'ima } & ||^{\text {'antigo' }} \\ & \text { L H }\end{array}$

Rio de Janeiro | Volume 16 | Número Especial Comemorativo | p. 280-315 | nov. 2020 
$\dashv \dashv \dashv\urcorner \dashv \dashv$

nõk ${ }^{\mathrm{h}}$ ima?̌rtsima

antigo- INTENS 1 -INTENS 2

' muitíssimo antigo' [[[nukima]itsi]ma]

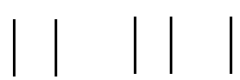

L H $\quad \mathrm{H} \quad \mathrm{L} \quad \mathrm{H}$

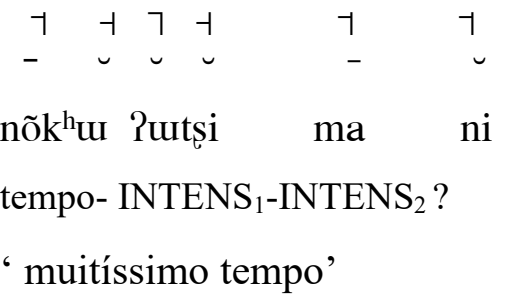

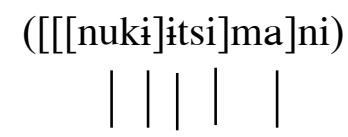

LH H L H

O exemplo em (7b) apresenta uma segunda duração longa (devida ao acento rítmico) sobre a primeira sílaba do primeiro sufixo (que representa o intensificador 1), sendo que essa segunda duração longa coincide com uma altura de voz muito alta que, por sua vez, é foneticamente diferenciada das alturas portadas pelas sílabas adjacentes. Já em (7c), observamos que a primeira sílaba após a raiz, concernente ao mesmo sufixo, mantém a altura muito alta, mas perde sua duração longa. A duração longa, no entanto, aparece sobre a única sílaba do sufixo que representa o intensificador 2. Pode-se observar igualmente que a altura portada por esse último sufixo é idêntica àquela com que é pronunciada a sílaba que o segue. Pelo que indicam tais dados, ao se ter, em determinados momentos, uma altura alta coincidente com uma duração longa, cria-se um elo perceptual entre ambas, o que pode permitir a supressão da própria duração longa, já que a altura alta garantiria a saliência perceptual da sílaba sobre a qual recai. Mas por que isso aconteceria? De onde proviria essa espécie de colaboração entre duração e altura da voz? Vamos dizer que a colaboração fornecida pela altura da voz não provém propriamente da estrutura métrica (organizadora do ritmo), mas de características e processos que, relativos à camada tonal, interagem perceptualmente com a estrutura métrica. Algumas dessas características encontram-se a seguir.

Em análise anterior do tom em Tikuna ${ }^{63}{ }^{64}$, argumentamos em favor de uma préassociação tonal no léxico, uma vez que essa evitaria os efeitos indesejáveis de uma associação tonal bidirecionada. Como consequência da pré-associação tonal, os morfemas da língua poderiam ter uma ou mais vogais associadas a um tom lexical, tal como se vê em (8) mais abaixo. Associadas a essa proposta, estiveram duas outras: a ) a da existência de um filtro lexical que inspecionaria a formação de palavras em estágios não-finais da derivação e que excluiria 
sequências trissilábicas associadas a um mesmo tom, conforme formalização em (9), em que o sinal de asterisco indica agramaticalidade, ao preceder uma dada sequência/construção; b) a da inserção do tom médio como default ao final de uma derivação, como mostrado por meio da regra em (10) e exemplificação em (11), em que se tem a representação de itens lexicais após a inserção do tom médio e suas respectivas realizações fonéticas ${ }^{65}$.

(8) Pré-associação tonal no léxico
a. pukire
b. pakara
c. orawe
d. popana $^{66}$

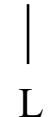
$\mathrm{L}$
'murapiranga'

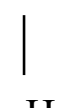
$\mathrm{H}$

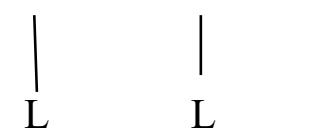
'cesto com tampa' ' barata' pássaro'

(espécie de árvore)

(9) Filtro lexical

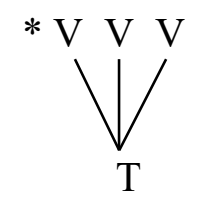

(10) Tom médio (default)

$\varnothing \rightarrow \mathrm{M}$
(11)a. pukire
b. pakara
c. orawe<smiles>[M]CC</smiles>
d. popana
$\dashv \dashv \dashv$
$\dashv \dashv \dashv$
$\dashv \dashv$
[pakara]

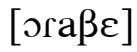
$\dashv \dashv \dashv$
[pokire]
'cesto com tampa' ' barata'
'tipo de pássaro)

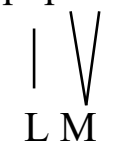
[popana]
'murapiranga'
(espécie de árvore)

O filtro lexical mostrado em (9) foi eliminado, em Soares (1999c), em favor de uma restrição associada a bloqueio de processos, tendo essa restrição sido identificada como OCP (Obligatory Contour Principle / Princípio do Contorno Obrigatório). Presente em nossa análise do tom em Tikuna desde $1994^{67}$, o OCP foi vinculado, inicialmente, nessa análise ${ }^{68}$, ao 
tratamento de dissimilações tonais, conforme formalização em (12) abaixo ${ }^{69}$. A partir de uma reformulação que assumiu as especificações tonais sustentadas em Soares (1998) e com a formalização em $(13)^{70}$, foi possível manter a resolução para os casos de dissimilação tonal e, ainda, cobrir aqueles cuja exclusão se devia ao filtro lexical - o que permitiu a eliminação desse último. Em (13), a terceira sílaba de uma palavra não pode ser associada ao mesmo componente tonal da segunda sílaba, se esse componente estiver associado à primeira sílaba através do nódulo tonal.

(12) Dissimilações tonais em Tikuna como uma conseqüência do Princípio do Contorno Obrigatório (OCP - Obligatory Contour Principle)

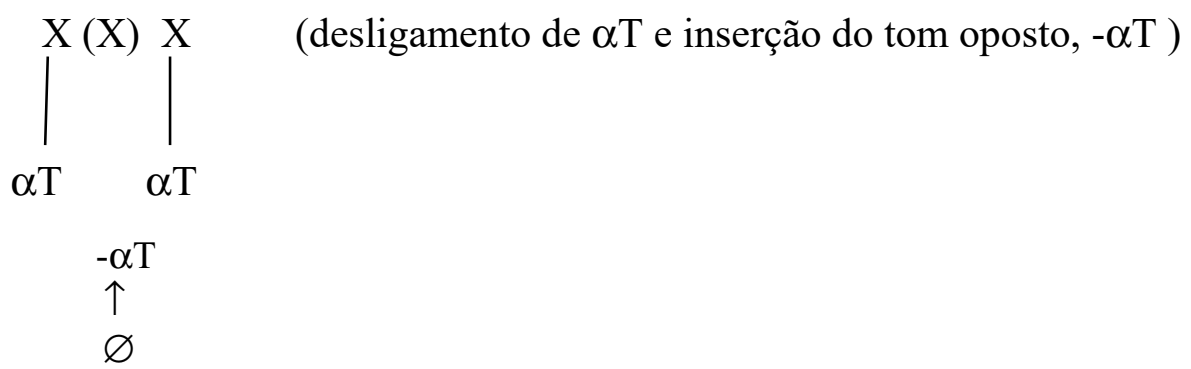

(13) OCP: uma sequência de especificações tonais idênticas está proibida

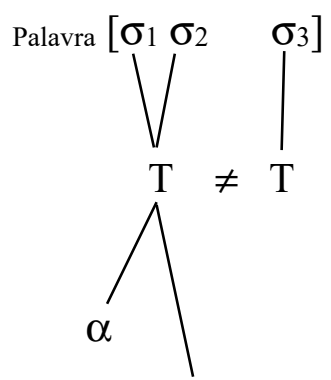

$(\alpha)$

Tanto a formalização em (12) quanto aquela em (13) permitem lidar com a dissimilação tonal na língua. Por exemplo, veja-se o dado em (14a), em que se tem o input fonológico de uma sequência já completamente construída, e o seu output (saída fonética) correspondente em (14b). O caminho derivacional que leva de (14a) a (14b) passa por estágios intermediários em que há sucessivas dissimilações tonais.

(14) a. Input fonológico

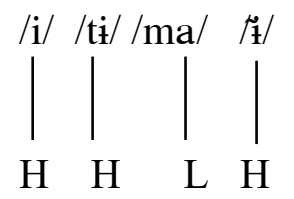

ASP PROGR -3 PF/C -matar, surrar- NOMLZR

'ele a surrou'

Rio de Janeiro | Volume 16 | Número Especial Comemorativo | p. 280-315 | nov. 2020 Celebrando mais de 50 anos do Programa de Pós-Graduação em Linguística da UFRJ e do percurso da Professora Emérita Miriam Lemle 


\section{b. Output (saída fonética)}

[/itimã̃]

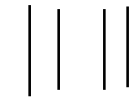

HL HL (estágios intermediários: HLLH; HLHH)

Os processos de dissimilação tonal na língua convivem com um outro fato: os tons não se espalham automaticamente, sendo que processos de espalhamento operam por sobre uma distância curta, alcançando não mais do que duas sílabas à esquerda ou à direita. Consequentemente, por efeito de características ligadas à camada tonal, cria-se em Tikuna uma alternância tonal por sobre uma extensão silábica relevante. Essa alternância independentemente constituída - produz uma colaboração entre duração e altura do ponto de vista perceptual. Em outros termos, devido a evidências empíricas, há uma boa razão para dizer que, em Tikuna, as fronteiras entre tom e acento estão sujeitas a uma interferência perceptual.

Se observados os dados do ponto de vista da colaboração entre altura e duração, temos que a alternância tonal passa a conviver com uma alternância acentual. A extensão silábica relevante sobre a qual ambas as alternâncias operam coincide com a linha do pé métrico. Sempre lembrando que, em Tikuna, a manifestação física do acento constitui-se de duração longa obtida por regra, voltemos ao acento, sobretudo ao acento rítmico.

O acento rítmico em Tikuna é explicável a partir de uma camada tonal completamente especificada. A propósito, vejam-se, novamente, os exemplos em (7b) e (7c), aqui repetidos como (15a) e (15b) sendo que, na representação mais abstrata de ambos, incluímos o acento rítmico (indicado, por razões didáticas, por um asterisco maior do que aquele referente ao acento linguístico):

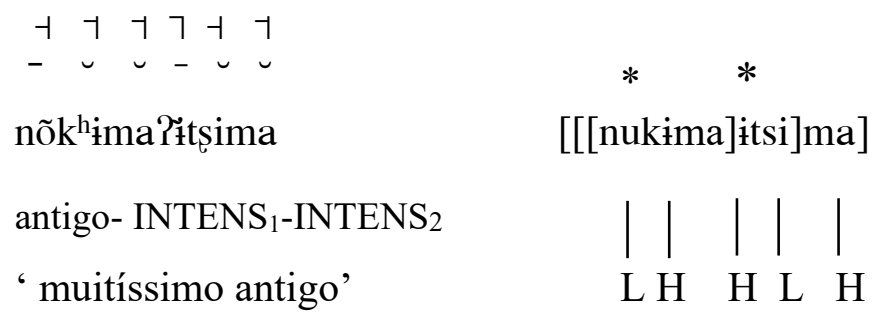

Rio de Janeiro | Volume 16 | Número Especial Comemorativo | p. 280-315 | nov. 2020 
$(15 b)$

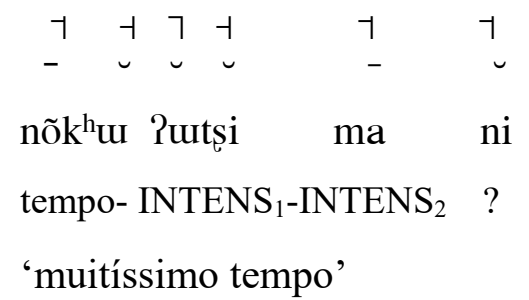

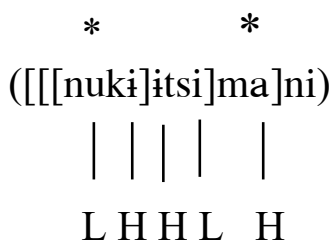

O que se observa nesses dados é que, devido à coincidência entre o acento rítmico e um ponto saliente derivado de restrições e processos que afetam tons, o acento rítmico visto em (15a) pode ser eliminado da sílaba em que era esperado e aparecer em outra sílaba mais adiante, tal como se vê em (15b). Um modo de lidar formalmente com esse fato estaria na representação conjugada do plano acentual, em que os acentos linguístico e rítmico(s) se encontrariam presentes, e do plano tonal, que exibiria as alternâncias tonais onde essas existissem. Esse tipo de representação não só tornaria visível a constituição, em Tikuna, de pés métricos binários ${ }^{71}$ com dominância à esquerda no plano acentual, mas também o possível ajustamento entre pé métrico e alternância tonal por efeito de processos que afetam, de forma independente, a camada tonal. Veja-se, por exemplo, uma representação nesses termos em (15c) a seguir. Correspondendo ao que se tem em (15b), a representação em (15c) deixa evidente a motivação que leva à eliminação do primeiro acento rítmico: a coincidência entre o acento ritmo e um ponto saliente pertencente a uma alternância na camada tonal. (Notar bem: no plano tonal, as variáveis $\alpha$ e $\beta$, ao anteceder tons adjacentes, indicam que esses diferem entre si).

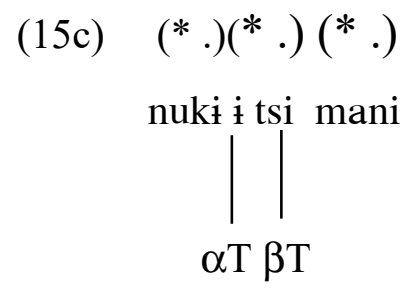

No que diz respeito especificamente a (15a), há aí o salto de uma sílaba breve (mă) situada entre dois pés métricos que, concebíveis como binários, apresentam seus respectivos núcleos em sua margem esquerda, sendo constituídos, respectivamente, pelo acento linguístico e por um acento rítmico, ambos manifestados foneticamente por meio de uma sílaba longa. Em outros termos, em (15a), os pés binários constituídos não seriam adjacentes, sendo que a nãoadjacência pode ser aí resolvida pela análise local fraca ${ }^{72}$, conforme representação correspondente em (15d) abaixo. Aparentemente, em Tikuna, no contexto de uma teoria da 
proeminência, "seria necessário, à primeira vista, lançar mão...da análise local fraca: uma opção marcada, ela permite que pés binários sejam construídos de maneira não-adjacente". ${ }^{73}$

\section{$(*) \quad(*$.}

(15d) nukima i tsi ma

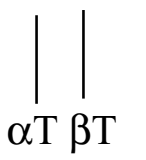

Com o fim de reunir mais evidências em favor de uma representação que congregue o plano acentual e o plano tonal, como a que se encontra em (15c) e (15d), acrescentemos o dado em (16) a seguir:

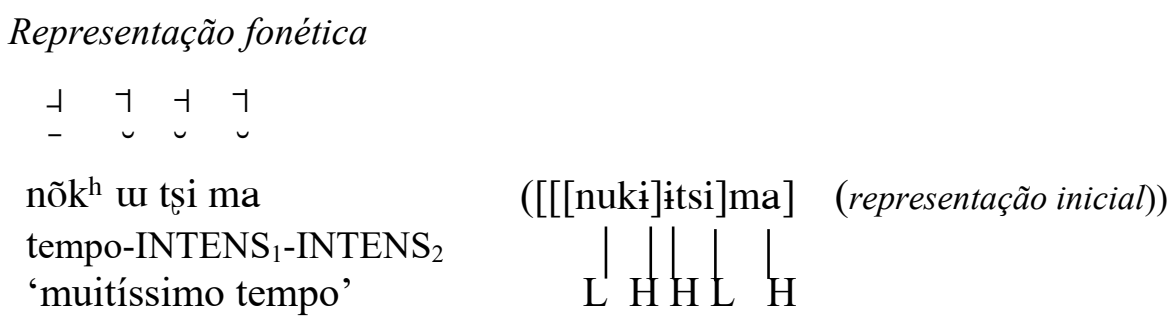

Comparando-se o que vimos sobre (15a) mais acima e com o que está em (16), temos uma situação parcialmente semelhante. Em (16), entre a sílaba da raiz que porta o acento linguístico (foneticamente manifestado por uma duração longa) e a sílaba breve que se encontra na margem direita da sequência, há duas outras sílabas foneticamente breves. Associados a essas duas sílabas materializadas como breves estão dois tons diferentes. Se admitida uma representação que congregue o plano acentual e o plano tonal, poderemos chegar à representação em (17), que, além de conter informações relevantes sobre o que ocorre em (16), permite explicar o que se dá nessa última. Na representação em (17), é possível notar uma coincidência entre o acento rítmico e um ponto saliente que, pertencente à camada tonal, participa de uma alternância tonal por sua vez ajustada a um determinado espaço rítmico: aquele de um pé métrico no plano acentual. Com isso, criam-se as condições para a eliminação do acento rítmico, o que, consequentemente, leva à redução da duração longa (materializadora do acento), que passa a se manifestar como breve, tal como visto no dado fonético em $(16)^{74}$. 


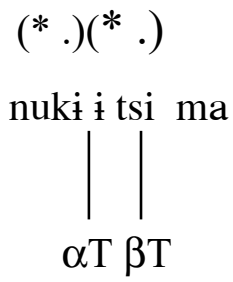

A representação em (17) vincula-se a (16), antecedendo-a. A partir de (17), é possível afirmar que não há aí qualquer salto de sílaba entre os pés binários que terminam por se materializar em (16). Quanto à adjacência entre pés binários visível em (17), essa não colocaria por terra a análise local fraca, já que, mesmo nas línguas que podem ser tratadas por meio dessa análise, essa somente pode ser aplicada a determinados dados se houver condições para isso ${ }^{75}$. No caso de (17), que se encontra no caminho derivacional de (16), o acento rítmico (tal como o acento linguístico) liga-se a uma duração longa. Isso faz com que uma sílaba passível de portar acento rítmico não seja saltada, mesmo se aceita a análise local fraca para o Tikuna.

Um modo de subsumir as representações em (15c), (15d) e (17) em uma única representação está em (18). Aí se contextualiza a eliminação do acento rítmico no âmbito de uma colaboração entre entre duração e altura da voz (pitch), focalizando-se somente as periodicidades rítmicas, conforme o modelo só-grade:

(18) Eliminação do acento rítmico

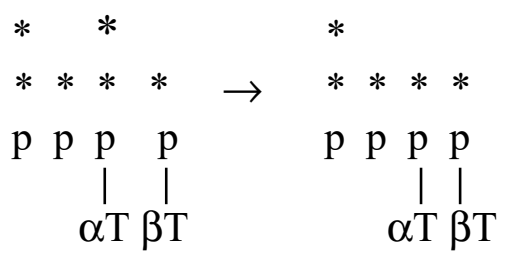

A representação em (18) nos permite afirmar que a eliminação do acento rítmico em Tikuna opera no nível da linha do pé métrico. Outras afirmações são possíveis a partir dos dados e formulações presentes nesta seção. Uma delas é que, para haver uma colaboração perceptual entre duração e altura, é preciso que a camada tonal esteja totalmente especificada. Outra é que, devido à possibilidade do seu à ajuste à duração, a altura pode servir à subdivisão de um espaço rítmico duracional. Outra ainda é que a eliminação do acento rítmico não integra uma situação de colisão acentual, como seria o esperado, e que tal eliminação parece ser a expressão de uma regra rítmica de nível mais baixo do que aquela responsável pela eliminação de acento por colisão ${ }^{76}$. Anos atrás, ao verificar o nível de ajustamento entre altura e duração em Tikuna, 
afirmamos que o crescimento de sequências para a direita está estreitamente relacionado a uma regulação que opera em mais de um plano - uma operação que pode ser ajustada seja de forma a que a regulação em um plano possa prosseguir em outro, seja de modo a harmonizar expectativas geradas com recursos de ambos os planos. ${ }^{77}$ No entanto, se observada a própria subdivisão do espaço rítmico duracional, que é coincidente com a de um pé métrico no plano acentual, pode-se constatar que tal subdivisão acompanha de perto a estruturação morfológica interna à palavra. Esse é um fato que nos permite dispensar a referência à margem direita da palavra como fator prosódico primeiro para o desencadeamento da constituição de pés métricos binários em Tikuna. Em outros termos, não seria a distância silábica relativamente à margem direita da palavra o fator primeiro ou único a guiar o ritmo binário que se observa nos dados dessa língua. Ao menos, para se lidar com esse ritmo binário e se alcançar uma generalização correta sobre o acento no âmbito da palavra em Tikuna, não se deveria deixar de lado o modo como são estruturadas as palavras na língua. Isso nos leva ao que é nosso último ponto neste artigo. Se a distância silábica relativamente à margem direita da palavra não é o melhor meio para se chegar a uma generalização correta sobre acento no domínio da palavra em Tikuna, deve-se voltar a atenção para os casos inequívocos em que a análise composicional da palavra mostra vinculação com a constituição de pés métricos e em que operações rítmicas ocorrem sem interferência perceptual proveniente de uma camada tonal totalmente especificada, dandose independentemente de informações sobre margem prosódica de palavra. Na seção a seguir, abordamos um desses casos.

\section{3-Composição e acento}

Em uma visão que assume a estruturação das formas linguísticas na constituição interna à palavra, compostos são estruturas com incorporação, em que o resultado é uma forma morfologicamente complexa que, identificada como palavra por seu comportamento morfológico e fonológico, contém duas ou mais raízes. Adotando a ideia de que compostos são formados quando um núcleo se incorpora a outro núcleo (em movimento de núcleo para núcleo ${ }^{78}$ ) e, ainda, que compostos são formados quando elementos frasais se concatenam a uma raiz antes de essa ser, por sua vez, concatenada a um nódulo terminal categorial ${ }^{79}$, teremos boas razões para considerar que os exemplos apresentados nesta seção constituem um caso de composição. Vejam-se a seguir os exemplos (19a) e (20a), referentes, respectivamente, a 'ele tem unha' e 'você está com as costas vermelhas'/ 'tuas costas estão vermelhas'. Ambos encontram-se representados em estágio posterior à aplicação das operações que levam à 
constituição da palavra. Nessas representações, consideramos que as raízes envolvidas em ambas foram concatenadas antes de sua categorização.

(19a) [ta [ [ã] [pati] $\left.\varnothing]_{v}\right]_{v P} \quad$ (ta '3PF/C' - ã 'ter' - patì 'unha') 'ele tem unha'

(20a) $\left[\mathrm{ku}[[\mathrm{dau}][\mathrm{kawe}]-\varnothing]_{\mathrm{v}}\right]_{\mathrm{vP}}(\mathrm{ku}$ '2'- dau 'vermelho' - kawe 'dorso, costas'

'você está com as costas vermelhas'/ 'tuas costas estão vermelhas' ${ }^{80}$

Se adotada a posição de Marantz (2002), segundo a qual a derivação de palavras se dá por fases, havendo linearização a cada anexação de morfema categorizador a uma estrutura, obteremos o passo a passo na construção das palavras aqui focalizadas, o que pode ser visto mais abaixo, nas representações em (19b, c, d, e, f, g) e em (20b, c, d, e, f). Na execução desse passo a passo, há que se prever o momento de negociação com a fonologia durante a construção da palavra. Para tanto, após as operações sintáticas e morfológicas teoricamente previstas nessa construção, também lidamos, nas representações mencionadas, com a informação fonológica relativa à camada tonal e com as informações relativas à grade métrica. Ao final, as sequências obtidas corresponderão às realizações referentes, respectivamente, a 'ele tem unha' e 'você está com as costas vermelhas'/ 'tuas costas estão vermelhas'. Lembramos que, de acordo com a hipótese de Marantz (2002), o significado da raiz e sua pronúncia são especificados na primeira anexação de morfema categorizador a uma raiz. E que novas anexações de morfema a essa estrutura formada representam contribuição composicional, tendo-se que levar em consideração significado e pronúncia já estabelecidos na fase anterior. Em (19b) e (20b), as raízes de ambas as construções se encontram concatenadas e categorizadas, dispondo de informação tonal onde essa está disponível nesse estágio da derivação. Quanto a (19c) e (20c), tem-se aí a possibilidade de construção da grade métrica, a partir da qual nota-se não só a existência de colisão acentual vinculável ao nível do pé métrico, mas também a proximidade entre essa categoria prosódica e fronteiras devidas à estruturação morfológica interna à palavra (proximidade que mesmo um modelo só-grade permite visualizar). A colisão acentual é fruto da concatenação de uma raiz monossilábica e de uma raiz dissilábica: como a atribuição de acento linguístico em raízes se dá por meio de alinhamento com a margem esquerda de cada raiz, daí resulta uma colisão acentual em (19c) e (20c):

Rio de Janeiro | Volume 16 | Número Especial Comemorativo | p. 280-315 | nov. 2020 
(19b) $[[\tilde{a}][\text { pati }]-\varnothing]_{\mathrm{v}}$

L H

ter-unha

(20b) $[[\text { dau }][\text { kawe }]-\varnothing]_{\mathrm{v}}$

$\begin{array}{ll}\mid & V \\ \mathrm{H} & \mathrm{L}\end{array}$

$* \quad *$

$* \quad * *$

(19c) $[[\tilde{a}][\text { pati }]-\varnothing]_{\mathrm{v}}$<smiles>C1=CCC1</smiles>

L H

ter-unha

* *

* $\quad * \quad *$

(20c) $[[\text { dau }][\text { kawe }]-\varnothing]_{v}$<smiles>C1CCCC1</smiles>

$\mathrm{H}$

$\mathrm{L}$

'estar com costas vermelhas'

Face à colisão acentual apontada, o acento portado pela segunda raiz de cada sequência construída é eliminado, conforme se vê em (19d) e (20d). Note-se que (19d) nos dá provas de que a operação de eliminação do acento portado pela segunda raiz não requer uma camada tonal completamente especificada, assim como (20d) nos mostra que a inexistência de uma alternância tonal associada à segunda raiz não impede a eliminação do acento portado por essa mesma raiz (ou seja, a alternância tonal não desempenha um papel nessa eliminação).

$*$

$* \quad * *$

(19d) $[[\tilde{a}][\text { pati }]-\varnothing]_{\mathrm{v}}$

$\mathrm{L} \mathrm{H}$

ter-unha

Rio de Janeiro | Volume 16 | Número Especial Comemorativo | p. 280-315 | nov. 2020 


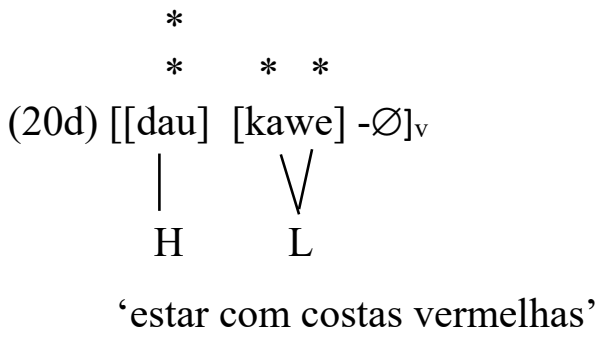

Por fim, em (19e) e (20e) tem-se a a concatenação do prefixo de pessoa às formas verbais constituídas, seguindo-se, a partir daí, a subordinação rítmica desse prefixo ao acento linguístico que permanece sobre a primeira raiz. Os passos seguintes incluem a inserção do tom médio como default onde essa é cabível (19f) e as implementações fonéticas que levam às realizações constantes em $(19 \mathrm{~g})$ e $(20 \mathrm{e})$. O resultado final, no que diz respeito às realizações fonéticas, mostram, em cada uma das sequências construídas, o acento linguístico (materializado pela duração longa) na antepenúltima sílaba, sem que a sua presença aí tenha sido pautada pela margem direita da palavra.

$(19 \mathrm{e}) \quad\left[\text { ta }[[\tilde{a}][\text { pati }]-\varnothing]_{\mathrm{v}}\right]_{\mathrm{vP}}$

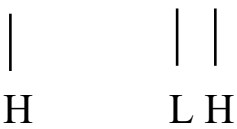

3PF/C-ter-unha

$(20 \mathrm{e})\left[\mathrm{ku}[[\mathrm{dau}][\mathrm{kawe}]-\varnothing]_{\mathrm{v}}\right]_{\mathrm{vP}}$<smiles>[14CH3][14CH2][14CH2][Tl]</smiles>

'2 -estar com costas vermelhas'

(19f) $\left[\text { ta }[[\tilde{a}][\text { pati }]-\varnothing]_{\mathrm{v}}\right]_{\mathrm{vP}}$

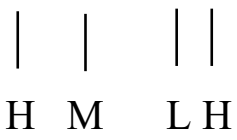

3PF/C-ter-unha 
$(19 \mathrm{~g})$ ta ã pati 'ele tem unha'

$\dashv \dashv \dashv$

$\checkmark-u$ u

(20f) kudavkaße

'você está com as costas vermelhas'/ 'tuas costas estão vermelhas'

Como a margem direita da palavra não se mostra, também em casos de composição, como fator determinante para a construção do ritmo em Tikuna no que seria o domínio da palavra, podemos colocá-la de lado igualmente nesses casos, focalizando apenas os elementos rítmicos que aí importam. Esses elementos incluem operações rítmicas no nível do pé métrico, havendo eliminação de acento linguístico sob colisão e independentemente de uma camada tonal completamente especificada. Aqui características e processos relativos à camada tonal não interagem perceptualmente com a estrutura métrica. E isso é uma indicação de que as operações rítmicas, nesse caso, se diferenciam daquelas em que tal interação perceptual existe, como visto em 2.

\section{3-CONCLUSÕES}

A partir do que vimos até aqui, é possível concluir, relativamente à participação da morfologia na construção do ritmo em Tikuna, que a atribuição do acento leva em conta as formas linguísticas em jogo na palavra, recebendo as raízes tratamento diferente daquele conferido aos afixos. A língua também exibe uma aparente alternância ternária, resolvível por meio da análise local fraca. Entre as conclusões mais importantes está a de se ter a possibilidade de dispensar a referência à margem direita da palavra como fator prosódico primeiro para $\mathrm{o}$ desencadeamento da constituição de pés métricos binários em Tikuna. Tal dispensa é possível quer em casos de sufixação, quer em casos de composição. Na sufixação, tem-se como possível o aparecimento do acento rítmico alimentado por uma espécie de colaboração, do ponto de vista perceptual, entre duração e altura da voz - colaboração essa que depende de uma camada tonal completamente especificada e que abre campo para operações rítmicas de nível mais baixo. $\mathrm{Na}$ composição, inexiste interação perceptual da altura da voz com a estrutura métrica, havendo indicações de que as operações rítmicas são aí diferentes daquelas de nível mais baixo. No que 
diz respeito à relação entre constituição morfológica e construção da grade métrica, observouse, durante a sufixação, que a própria subdivisão do espaço rítmico duracional é coincidente com a de um pé métrico no plano acentual, tendo-se constatado que tal subdivisão acompanha de perto a estruturação morfológica interna à palavra, sendo que o mesmo se dá em casos de composição.

Os casos observados no âmbito da palavra em Tikuna mostram que a categoria prosódica relevante é o pé métrico, categoria prosódica vinculável a uma linha métrica baixa. No que diz respeito à liberdade do ritmo associável a essa linha métrica (hipótese de Soares 1992), as perspectivas que se abrem para o estudo do ritmo na língua aqui focalizada prevêem algumas inclusões. Uma delas, necessariamente, é realizar investigação sobre palavras funcionais, em contraste com aquelas comumente tidas como lexicais, verificando-se (e revendo-se ${ }^{81}$ ) o modo como, em Tikuna, padrões acentuais são levados para o nível frasal. Uma outra é associar, sob a mesma ótica teórica, o estudo de sintaxe interna à palavra (que foi aqui ensaiado) e o estudo de sintaxe para além da palavra. Ambas as inclusões são parte de estudos por desenvolver.

\section{ABREVIATURAS E SÍMBOLOS}

ASP PROGR

CL

DAT

INTENS

LOC

NOMLZR

$\mathrm{PF} / \mathrm{C}$

PL

V

n aspecto progressivo forma pronominal clítica (clítico sintático)

dativo

intensificador

locativo

nominalizador

marca de pessoa familiar ou de consideração

plural

categoria funcional constituída de feixe de traços e criadora da categoria lexical verbo

categoria funcional constituída de feixe de traços e criadora da categoria lexical nome

primeira pessoa

segunda pessoa

terceira pessoa

Rio de Janeiro | Volume 16 | Número Especial Comemorativo | p. 280-315 | nov. 2020 


$\begin{array}{ll}\phi & \text { frase fonológica } \\ \omega & \text { palavra prosódica } \\ \Sigma & \text { pé métrico } \\ \sigma & \text { sílaba } \\ \mathrm{P} & \text { material fonético } \\ - & \text { duração longa } \\ - & \text { duração breve } \\ \neg & \text { altura alta elevada (extra hight pitch) } \\ \dashv & \text { altura alta (hight pitch) } \\ \dashv & \text { altura média (mid pitch) } \\ \lrcorner & \text { altura baixa (low pitch) } \\ \lrcorner & \text { altura baixa abaixada (extra low pitch) } \\ \mathrm{T} & \text { tom } \\ \mathrm{H} & \text { tom alto (high tone) } \\ \mathrm{M} & \text { tom médio (mid tone) } \\ \mathrm{L} & \text { tom baixo (low tone). }\end{array}$

\section{REFERÊNCIAS}

BAKER, M. C. Incorporation: a theory of grammatcal function changing. Chicago: University of Chicago Press.

BOLOZKY, S. (1982) "Remarks on rhythmic stress in Modern Hebrew". Journal of Linguistics 18: 275-289.

BRUCE, G., J. Frid e I. Thelander (2004) Swedish Accent Navigation. International Symposium on Tonal Aspects of Languages with Emphasis on Tone Languages. Beijing, March 28-31. Disponível em: (http://www.lunduniversity.lu.se/o.o.i.s?id=24732\&postid=750474)

EMBICK, D e M. Halle (2005) "On the status of stems in morphological theory". Em T. Geerts e H. Jacobs (editores). Proceedings of Going Romance 2003. Amsterdam/Philadelphia: John Benjamins, 59-88.

HALE, K. e S. J. Keyser (2002). Prolegomenon to a theory of l-syntax. Cambridge: MIT Press.

HALLE, M. e J.-R. Vergnaud (1987) An essay on stress. Cambridge: MIT Press.

HALLE, M. e W. Idsardi (1995) "General properties of stress and metricals tructure". Em J. A. Goldsmith (editor). The handbook of phonological theory. Oxford: Blackwell, 403-443.

HARLEY, H. (2003) "Merge, conflation, and head movement: The First Sister Principle". Em K. Moulton (editor). Proceedings of NELS 34. U. Mass Amherst: GSLA, 239-254. 
. (2009) "Compounding in Distributed Morphology". Em R. Lieber e P. Štekauer (editores). The Oxford handbook of compounding. Oxford: Oford University Press, 129-144.

HAYES, B. (1995) Metrical stress theory. Principles and case studies. Chicago/London: The University of Chicago Press.

IDSARDI, W. (1992) The computation of stress. PhD Dissertation. Cambridge: Massachusetts Institute of Technology (MIT).

KAISSE, E. (2005) "The interface between morphology and phonology". Em P. Stekauer e R. Lieber (editores). Handbook of English Word-formation. Dordrecht: Springer, 25-47.

KEY, H. (1961) "Phonotactics of Cayuvava". International Journal of American Linguistics 27, n.2: $143-150$.

LIBERMAN, M. e A. Prince (1977) "On stress and linguistic rhythmic”. Linguistic Inquiry 8: 249-336.

MARANTZ, A. (2002) Handout on Derivational Morphology. Disponível em: http://web.mit.edu/ marantz/Public/ALI/Handouts.

MINER, K. L (1979) "Dorsey's law in Winnebago-Chiwere and Winnebago accent". International Journal of American Linguistics 45: 25-33.

. (1981) "Metrics, or Winnebago made harder". International Journal of American Linguistics 47: 340-342.

NESPOR, M. e I. Vogel (1989) “On clashes and lapses”. Phonology 6: 69-116.

NESPOR, M. (1990) "On the separation of prosodic and rhythmic phonology". Em S. Inkelas, S. e D. Zec (editores). The phonology-syntax connection. Chicago/London: The University of Chicago Press.

NEWMAN, S. (1944) Yokuts language of California. New York: Viking Fund Publications in Anthropology.

PRINCE, A. (1980) “A metrical theory for Estonian quantity”. Linguistic Inquiry 11, 511-562. . (1983) "Relating to the Grid". Linguistic Inquiry 14: 19-100.

. (1985) “Improving Tree Theory”. Berkeley Linguistics Society 11: 471-490.

SELKIRK, E. (1980a) On prosodic to structure and its relation to syntactic structure [1978]. Bloomington: Indiana University Linguistics Club.

11: $563-605$

(1980b) "The role of prosodic categories in English word stress". Linguistic Inquiry MIT Press.

(1984) Phonology and syntax: the relation between sound and structure. Cambridge: 405.

(1986) "On derived domains in sentence phonology". Phonology Yearbook 3: 371-

SOARES, M. F. (1991) “Aspectos suprassegmentais e discurso em Tikuna”. Em E. Orlandi (editora). Discurso indígena. A materialidade da língua e o movimento da identidade. Campinas, SP: Editora da Unicamp, 45-138. 
. (1992) O supra-segmental em Tikuna e a teoria fonológica. Volume I: Investigação de aspectos da sintaxe Tikuna. Volume II: Ritmo. Tese de doutorado. Campinas: Universidade Estadual de Campinas (Unicamp).

. (1994) "Do tratamento fonológico do ritmo". Letras de Hoje, v. 29, nº 4, p. 7-23.

(1995a) "Ritmo y tono en tikuna". Actas de las Segundas Jornadas de Linguística Aborigen [1994]. Buenos Aires: Universidad de Buenos Aires, Facultad de Filosofía y Letras, Instituto de Linguística, 147-161.

. (1995b) "Núcleo e coda. A sílaba em Tikuna". Em L. Wetzels (organizador). Estudos fonológicos das Línguas Indígenas Brasileiras. Rio de Janeiro: Editora UFRJ, 195-263.

7-26.

(1996) "Regulação rítmica e atuação do OCP em Tikuna". Letras de Hoje, v.31, n.2:

. (1998) "Sous-spécification tonale em Tikuna". Actes du 16e Congrès des Linguistes. Oxford: Elsevier Sciences.

. (1999a) “A contribuição do Tikuna às regras do ritmo e às relações sintaxe-fonologia”. Em E. M. Scarpa (organizadora). Estudos de Prosódia. Campinas, SP: Editora da Unicamp, $189-252$.

(1999b) "Clitics in Tikuna: a minimalist approach”. Palestra proferida no quadro do grupo de pesquisa em sintaxe do Departamento de Lingüística da Universidade de Toronto, Canadá.

(1999c) "Ritmo em Tikuna: un abordaje basado en restricciones". Actas del I Congreso de Lenguas Indígenas de Sudamérica. Lima: Universidad Ricardo Palma, Facultad de Lenguas Modernas.

. (2000) O supra-segmental em Tikuna e a teoria fonológica. Volume I: Investigação de aspectos da sintaxe Tikuna. Campinas, SP: Editora da Unicamp.

. (2001) "Subespecificação tonal e tom default: o caso Tikuna". Em A. S. A.C. Cabral e A. D. Rodrigues (organizadores). Estudos sobre linguas indígenas I. Belém: UFPA, 9-35. 4: $63-88$

. (2003) "Línguas indígenas: caminhos de uma investigação". Letras de Hoje, v. 38, n.

(2005) “Da representação do Tempo em Tikuna". Em A. D. Rodrigues e A. S. A.C.

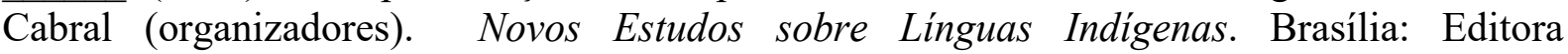
Universidade de Brasília, 153-167.

(2010) "Categorias funcionais e conhecimento enciclopédico ou sintaxe e significado no domínio verbal: noções aspectuais e expressão da causatividade em Tikuna”. Revista Estudos da Linguagem, v.18, n.1: 187-234.

SOARES, M. F. e G.N. Damulakis (2007). "Do princípio do contorno obrigatório e línguas faladas no Brasil”. Revista Estudos da Linguagem, v. 15, n. 2: 229-252.

Rio de Janeiro | Volume 16 | Número Especial Comemorativo | p. 280-315 | nov. 2020 


\begin{abstract}
${ }^{1}$ Soares (1992) é um trabalho constituído de dois volumes. O primeiro deles encontra-se publicado (Soares (2000).
${ }^{2}$ Do lado brasileiro, é elevado o número de comunidades Tikuna (atualmente, acima de cem), localizadas em diferentes municípios do estado do Amazonas.

${ }^{3}$ Ver a propósito, por exemplo, Embick \& Halle (2005) e Harley (2008).

${ }^{4}$ Esse tipo de admissão é bastante claro em trabalhos vinculados teoricamente à Fonologia Lexical (discutida em detalhe, por exemplo, por Kaisse (2005)). Mesmo um quadro teórico que não lida com a presença de um léxico gerativo na arquitetura da gramática, como é o caso da Morfologia Distribuída, a questão da pronúncia não é excluída, já que a posição ocupada na superfície pelo material fonológico pode fornecer indicações sobre a posição de elementos mais abstratos na representação subjacente (elementos que o material fonológico concretiza).
\end{abstract}

${ }^{5}$ Veja-se, por exemplo, Hayes (1995) em confronto com Halle e Vergnaud (1987). O primeiro indica o núcleo do pé por um $\mathrm{x}$, enquanto os últimos o fazem através de um asterisco. Essa diferença não é puramente notacional, estando associada a outras diferenças de cunho teórico envolvendo os autores dessas duas obras (ver notas 11 e 12, mais adiante).

${ }^{6}$ Pés não delimitados, também conhecidos como unbounded, se fazem presentes, via de regra, em sistemas sensíveis à quantidade. Prince (1985) propôs sua eliminação como noção primitiva, isto é, pés unbounded não fariam parte do vocabulário primitivo da teoria parametrizada dos padrões acentuais lexicais.

${ }^{7}$ A essa descrição corresponde a seguinte representação do troqueu silábico, em que x indica núcleo do pé métrico: $(\mathrm{x}$.

$\sigma \sigma$

É importante notar que, na proposta de Hayes (1995), exclui-se a existência de iambos silábicos, isto é, de pés métricos que, constituídos de sílabas, tenham seu núcleo na margem direita. A motivação apresentada por Hayes (1995) para uma tal exclusão está em uma determinada concepção da chamada Lei Trocaica/Iâmbica. Com origens colocadas em domínios rítmicos que incluem, por exemplo, a música, essa lei não se circunscreveria ao que é linguístico, embora seu reflexo seja encontrado nas línguas naturais. Pela Lei Trocaica/Iâmbica, elementos que contrastam em intensidade formam grupamentos com proeminência inicial; e elementos que contrastam em duração formam grupamentos com proeminência final. Os efeitos dessa lei no âmbito do que é linguístico levam, na visão de Hayes (1995: 79-82), a um inventário de pés básicos assimétrico, no qual não há lugar para iâmbicos silábicos, e sim para troqueus silábicos, troqueus moraicos e iâmbicos moraicos (ou simplesmente iambos, por serem sempre moraicos).

${ }^{8}$ As duas possibilidades apontadas para o troqueu moraico correspondem, respectivamente, às seguintes representações:
(i)
(x .)
(ii) $(\mathrm{x})$

Com isso, a se levar em conta Hayes (1995: 71), o conhecido troqueu latino, em que se tem uma duração longa seguida de duração breve, fica excluído do conjunto de representações referentes ao troqueu moraico. Em outros termos, Hayes (1995) não admite, em seu inventário de pés básicos, a existência de troqueu moraico desbalanceado. No entanto, o mesmo autor, com base na Lei Trocaica/Iâmbica (rever nota 7), cria um lugar, nesse mesmo inventário, para a admissão do iambo latino, isto é, para o iambo moraico desbalanceado (no qual uma duração breve é seguida por uma duração longa), conforme apontado em passagem um pouco mais à frente.

${ }^{9}$ A primeira possibilidade mencionada para o iambo moraico (em que o núcleo pode conter uma ou duas moras) corresponde à representação em (i) a seguir, por sua vez desdobrável em (i)a e (i)b. Quanto à outra possibilidade apontada, sua representação corresponde ao que se tem em (ii), também a seguir.

(. $\mathrm{x})$

(i)a. (. x)

(i)b. (. x)

(ii)

$$
(\mathrm{x})
$$

${ }^{10}$ Cf. Hayes (1995: 86; 102).

${ }^{11}$ Sobre as diferenças entre o modelo de Halle \& Vergnaud (1987) e Hayes (1995), ver Soares (1994). Quanto a Idsardi (1992), esse filia-se a Halle e Vergnaud (1987), mas inova ao propor que apenas um parêntese (à esquerda ou à direita) é necessário para agrupar marcas de grade, uma ideia levada adiante em Halle e Idsardi (1995).

${ }^{12}$ Para as diferenças entre os modelos de Selkirk (1984) e Nespor e Vogel (1989) / Nespor (1990), ver, por exemplo, Soares (1999a). Sobre pontos referentes à relação sintaxe-fonologia nesses modelos, veja-se especialmente Soares (1999a: 207-213).

${ }^{13}$ Halle \& Vergnaud (1987), por exemplo, os aceitaram em parte e sob condição: pés ternários seriam construídos apenas sob o formato $\left({ }^{*}\right.$.), isto é, sob tal condição, o núcleo não é adjacente a uma das fronteiras do pé e entre essas e o núcleo não há mais do que um elemento interveniente - o que é fruto dos parâmetros assumidos por esses autores. Isso significou a eliminação automática, do conjunto possível de pés métricos, de dátilos (constituídos de uma duração longa e duas breves) e de anapestos (formados por duas durações breves e uma longa). Já Hayes (1995) rejeitou totalmente a ideia de haver pés ternários básicos.

${ }^{14}$ Cf. Hayes (1995: 308). 


\begin{abstract}
${ }^{15}$ Idem, ibidem.
${ }^{16}$ Um exemplo esquemático de impossibilidade a respeito é fornecido por Hayes (1995: 309): em um caso analisável por troqueus moraicos (independentemente da direção de análise) e passível de tratamento via análise local fraca, sequências que comportem duas durações longas adjacentes na janela de análise deverão ser tratadas como dois pés adjacentes, por não haver duração breve a ser saltada.
\end{abstract}

${ }^{17}$ A nosso ver, tais pontos de ambiguidade abrem, em determinadas situações, possibilidades de contato entre um sistema e outro. Entre os casos conhecidos compatíveis com a análise local fraca, estão, por exemplo, o Cayuvava e o estoniano. O Cayuvava é uma língua analisável por troqueus silábicos que podem, porém, ser assumidos como troqueus moraicos constituídos apenas de durações breves, uma vez que a língua não apresenta sílabas longas/pesadas (ver nota 27). Quanto ao estoniano, língua fino-úgrica, essa já foi analisada como possuindo um pé métrico definido por duas unidades, sendo essa unidade sílaba ou mora. Quando essa unidade é tida como sendo a mora, uma sílaba longa (pesada) deixada de lado durante a análise de uma palavra em pés métricos pode ser considerada como constituindo um pé default, já que possui duas moras (conforme regras constantes de Prince, 1980:534), ou mesmo como um default aplicável a troqueus silábicos em geral (de acordo com Hayes, 1995: 320). O estoniano também apresenta durações ultralongas. Essas foram tratadas por Hayes (1995: 328) por meio de determinados recursos, um dos quais foi a representação moraica do ultralongamento. Esse último autor, que se inspira na análise de Prince, recorre à representação moraica para lidar com determinados aspectos da duração em estoniano, sem deixar, porém, de considerar essa língua como analisável por meio de troqueus silábicos cuja distância prosódica está opcionalmente ligada à análise local fraca. Segundo Hayes (1995:329), "the foot template of Estonian simply does not care about the quantity of the syllables it dominates, whereas the weak local parsing algorithm can skip over only light syllables. The indirect method of referring to syllable weight provides the flexibility needed to describe Estonian pattern".

${ }^{18}$ Categoria prosódica situada abaixo da frase fonológica e acima da palavra prosódica, o grupo clítico não é assumido por Nespor \& Vogel (1989) para toda e qualquer língua, mas somente para aquelas línguas em que o mesmo se revela como estrutura crucial para o tratamento do ritmo. Esse é o caso, por exemplo, do polonês, língua em que a postulação do grupo clítico permite explicar a diferença entre compostos e frases (sintagmas) com respeito à definição de colisão. Nas palavras das próprias autoras, "If we group the phonological words that make up a compound into a single group, we can thus distinguish them prosodically from phonological words that are part of the same phonological phrases but do not constitute a compound."(Cf. Nespor e Vogel (1989: 105)). A admissão do grupo clítico para uma língua como o polonês leva à previsão de que clíticos e seus hospedeiros exibirão comportamento prosódico semelhante ao dos membros de um composto (idem, ibidem).

${ }^{19}$ Ver Nespor \& Vogel (1989).

${ }^{20}$ No caso das três línguas mencionadas (italiano, catalão e grego), esses elementos corresponderiam a sílabas.

${ }^{21} \mathrm{O}$ grupo clítico não se faz presente nos esquemas em (1a) e (1b). Sobre sua ausência, rever nota 18.

${ }^{22}$ No interior da grade métrica, as periodicidades rítmicas são indicadas por marcas acentuais (acentos) representadas por $\mathrm{x}$ ou asterisco, cabendo observar que, quando se encontram na linha métrica mais baixa, tais marcas não indicam propriamente acentos, mas posições acentuáveis. Para a indicação das periodicidades rítmicas, nossa opção foi pela adoção do asterisco (que, conforme já mencionado, também poderia ser usado para indicar o núcleo de cada pé métrico).

${ }^{23}$ Em termos teóricos, a grade métrica e a estrutura prosódica não estão no mesmo plano, nem revelam os mesmos tipos de processo. À estrutura prosódica estariam relacionados, por exemplo, os processos de sândi, enquanto à grade métrica ligam-se as regras do ritmo. Por desejarmos mostrar claramente a que categoria prosódica se vincularia uma definição de colisão acentual em uma dada língua, colocamos lado a lado os esquemas referentes à grade métrica e à estrutura prosódica em (1a) e (1b), sem comprometimento, porém, da ideia de que se encontram em planos diferentes. Segundo Nespor \& Vogel (1989), que mencionam a visão de Nespor (1990), a grade métrica e a estrutura prosódica não são constructos teóricos que estejam em um mesmo plano. Na realidade, em Nespor (1990), a estrutura prosódica é intermediária entre a sintaxe e o componente prosódico da fonologia pós-lexical. Quanto à grade métrica, essa realiza a intermediação entre a fonologia prosódica e a fonologia do ritmo. Apesar disso, conforme Soares (1999a: 210-211), existe "a possibilidade de recuperação de uma certa quantidade de informação prosódica sobre a sentença a partir da grade métrica, a se levar em conta Nespor e Vogel (1989, p. 71): porque realiza a intermediação entre a fonologia prosódica e a fonologia do ritmo, a grade métrica pode permitir uma tal recuperação antes que as operações de grade modifiquem o padrão rítmico da sentença. A recuperação da informação prosódica sobre a sentença fica, assim, restrita a um nível de representação que é anterior à aplicação das regras do ritmo, e esse nível de representação é, pelas indicações dadas, resultado da aplicação das regras que constroem a grade métrica".

${ }^{24}$ Os parênteses aqui indicam a presença opcional de acento no nível da palavra prosódica.

${ }^{25}$ A solução fornecida por Nespor \& Vogel (1989) para esse caso de colisão reside basicamente em um enfraquecimento de um dos acentos ocupantes da linha métrica em que a colisão acentual mínima é definida (ver também, a propósito, Soares (1999a: 199-200)).

${ }^{26}$ Cf. Hayes (1995: 367).

${ }^{27}$ O Cayuvava (Bolívia) já foi considerado como possuindo um acento não-persistente, isto é, como uma língua em que a estrutura métrica é atribuída uma única vez durante a derivação. Nessa atribuição, constituem-se alternâncias ternárias que podem ser tratadas como resultantes da construção, da direita para a esquerda, de pés binários não-adjacentes, ou seja, com a interveniência de uma sílaba breve saltada entre os pés (por efeito da análise local fraca). Os pés são silábicos e possuidores de núcleo à esquerda. Em princípio, são troqueus silábicos que podem, porém, ser assumidos como troqueus moraicos constituídos apenas de durações breves, já que a língua não apresenta sílabas longas/pesadas (rever nota 17). Tais Rio de Janeiro | Volume 16 | Número Especial Comemorativo | p. 280-315 | nov. 2020 Celebrando mais de 50 anos do Programa de Pós-Graduação em Linguística da UFRJ e do percurso da Professora Emérita Miriam Lemle 
características convivem com extrametricidade na margem direita - o que significa que a sílaba na margem direita é invisível para fins de atribuição de acento (exceto em determinados contextos morfológicos; ver nota 35). Além disso, a língua admitiria pés constituídos de uma única sílaba (pés dgenerados) em posição forte e, em grandes extensões silábicas, apresentaria duas sílabas desgarradas (fora de qualquer pé), na margem esquerda da palavra, também devido à análise local fraca. A regulação rítmica operada no nível do pé métrico em Cayuvava (e que levaria à possibilidade da existência de padrões alternantes para além das fronteiras de palavra) pode, no entanto, ser submetida ao acento final de palavra em análise do tipo top-down, pela qual o acento de palavra deve ser atribuído antes dos acentos vinculados aos pés. Essa é, de fato, a análise adotada para o Cayuvava por Hayes (1995: 117; 309-314). Sobre um provável parentesco do Cayuvava com outras línguas, Key (1961:143, nota 3) apresenta o seguinte panorama: "J. Alden Mason (The Languages of South American Indians, Handbook of South American Indians, Bulletin 143, Vol. 6, 273) summarizes the proposed relationships as follows: Loukotka (1935) saw evidences of Arawak intrusion in Cayuvava and Markham (1910) considered it a branch of Mojo, but there has been no evidence presented for its wider relationships. Crequi- Montfort and Rivet (1920) found some lexical resemblance to Guaicuru but not enough to assume any relationship; some, but even less resemblance was found to Tuyoneiri, Canichana, and Movima".

\begin{abstract}
${ }^{28}$ Newman (1944: 28-29) apresenta variações referentes à realização de uma sentença em Yawelmani correspondente ao que, inglês, seria "you, then, will not tell my wife". Nas palavras do próprio autor: "Cutting across the phenomenon of word stress is that of cadence, or phrase stress. A group of words composing a phrase is pronounced as a stress unit, taking the stress on the penultimate syllable. Nouns and verbs tend to keep their word stress unmodified in phrases, largely by acting as the phrase nucleus in drawing to themselves any preceding unaccented words. But pronouns, demonstratives, and particles, especially those of one syllable, vary their stress according to their position in the phrase. However, the grouping of words into phrases is extremely plastic, for a given sentence may shift its words into varying phrase patterns..." (idem, p. 28).
\end{abstract}

${ }^{29}$ No nível frasal, o Tikuna também exibe operações rítmicas no nível da linha do pé, confome Soares (1992). Em Soares (1999a: 239-244), lê-se que, em Tikuna, no nível frasal, "a operação que se dá para além da palavra é a de um apagamento ocorrido nível do pé". E as situações de subordinação rítmica aí apresentadas exemplificam: a) a "não-obrigatoriedade de colisão acentual entre acentos linguísticos que constituem uma configuração na qual irá operar o apagamento de um entre dois acentos"; b) "bilateralidade da operação de apagamento"; c) "possibilidade de ocorrência de nivelamento tonal na extensão de sílabas sob domínio do acento" (idem, ibidem).

${ }^{30}$ Os padrões acentuais alternantes do sueco seriam atribuídos sem respeito às fronteiras de palavra segundo Bruce (1984) (apud Hayes (1995): 367) [Bruce, G. (1984) "Rhythmic alternation in Swedish". Em C.-C Elert, I. Johansson e E. Strangert (editores). Nordic Prosody III. Estocolmo: Almqvist \& Wiksell International]. Em Bruce, Frid e Thelander (2004), lê-se que, diferentemente de muitas línguas europeias, o sueco, o norueguês e o dinamarquês são caracterizados por possuir uma oposição entre dois acentos de palavra. Tais acentos parecem desempenhar um papel central na prosódia escandinava, sendo que são chamados de acento I e acento II no tratamento do sueco e do noruguês - línguas em que o principal correlato fonético do acento é tonal [sic]. Mais adiante, no mesmo trabalho, fica clara, para o sueco, a importância do acento secundário, que entendemos possuir participação nos padrões acentuais alternantes. Conforme os mesmos autores, palavras simples (que possuem um só acento), são metricamente distintas de palavras compostas (possuidoras de dois acentos - um acento primário no primeiro elemento e um secundário no elemento final do composto). Essa distinção, no entanto, pode desaparecer entoacionalmente (ou seja, em termos de proposta de uma fonologia prosódica, no nível da frase entoacional). Ainda segundo os autores, em alguns tipos de dialeto do sueco, o acento secundário pode desempenhar um papel importante como ponto de sincronização da altura da voz (pitch). No sueco do leste (Svea), o acento secundário é um gatilho (trigger) para a ascensão do acento focal, enquanto no sueco central (Dalarna) é a queda (descenso) do acento de palavra (focal ou não focal) que é engatilhada pelo acento secundário.

${ }^{31}$ De acordo com Bolozky (1982: 275-277), no hebreu moderno, o acento principal ocorre basicamente no final de palavra, exceto em uns poucos ambientes (e alguns grupos de itens lexicais), nos quais o acento ocupa a penúltima posição. Outras sílabas na palavra portam acento subsidiário (secundário) que é basicamente do tipo alternante: esse recai na segunda sílaba à esquerda do acento principal e, de modo iterativo, a cada duas sílabas à esquerda, indo completamente até o início da palavra. Entre os exemplos fornecidos por Bolozky (1982), estão: mèvugár 'adult'; amèvugár ' the adult'; vèkešèamèvugár ' and when the adult'; àmevùgarím 'the adults'; kèšeàmevùgarím 'when the adults'. Ainda de acordo com Bolozky (1982), a distribuição do acento secundário é automática em hebreu moderno: tudo o que se exige é a descrição da localização do acento principal, sendo o resto puro ritmo. Vale registrar que uma diferença básica é que, na visão do autor, a marcação lexical do acento em hebreu moderno é mínima e que o acento final regular é atribuído no nível da palavra flexionada/derivada, sendo o acento secundário atribuído no nível da palavra fonológica. Para Bolozky (1982), é possível que, em hebreu moderno, a palavra fonológica seja o domínio tanto do acento principal quanto da distribuição do acento secundário. De qualquer modo, ainda na visão do mesmo autor, o acento em hebreu moderno é apenas marginalmente lexical e seu domínio (pelo menos no que diz respeito ao acento secundário) é mais amplo do que a 'palavra' (mot) de Liberman \& Prince (1977) ou do que a palavra prosódica de Selkirk (1978/1980a, 1980b), que corresponde à palavra sem clíticos (cf. Bolozky (1982: 277)).

${ }^{32}$ Cf. Hayes (1995: 31-32).

${ }^{33}$ Língua não-classificada, Equador. Hayes (1995: 182-188).

${ }^{34}$ Língua Uto-Asteca, Califórnia do sul. Hayes (1995: 132-134) assume que o Cahuilla é um sistema acentual do tipo topdown, com a camada da palavra constituída em primeiro lugar.

35 Em Cayuvava, por exemplo, certas formas verbais imperativas recebem acento final, havendo também sufixos monossilábicos pré-acentuados (idem, p.312). Reveja-se a nota 27. 


\footnotetext{
${ }^{36}$ Também chamado de Alutiiq, o Koniag é uma das línguas Yupik. Ver Hayes (1995:333).

37 Ver Hayes (1995:210).
}

${ }^{38} \mathrm{O}$ Paamês (língua austronésia, Vanuatu) apresenta extrametricidade silábica na margem direita da palavra e também extrametricidade de pé métrico nessa mesma margem (ou seja, a sílaba final e, do mesmo modo, o último pé são invisíveis para atribuição de acento de palavra). Como a língua também não aceita pés degenerados, tal conjunto de características tem consequências acentuais sobre o acento final de palavra (que deve ser à direita). Um caso que chama a atenção é aquele referente a raízes que não possuem extensão suficiente para comportar dois pés e em que o material fonológico restante da própria raiz não poderá constituir pé (o que ocorre com raízes ternárias, por exemplo). Nesse caso, havendo prefixo precedendo esse tipo de raiz, a língua apresentará acento pré-antepenúltimo - fato que convive, na língua, com formas que exibem acento em penúltima e antepenúltima posição.

${ }^{39}$ Segundo Hint (1973) (apud Hayes (1995:316), em estoniano (língua fino-úgrica), cada acento morfologicamente delimitado, primário ou secundário, inicia sua própria palavra fonológica, que pode ser menor do que uma palavra gramatical [Hint, Mati (1973). Eesti Keele Sönafonoloogia I, Eesti NSV Teaduste Akadeemia, Tallinn, Estonia.] É preciso registrar, porém, que, fora da situação de acento morfologicamente delimitado, em estoniano o acento principal recai comumente na sílaba inicial da palavra e que o acento secundário é amplamente previsível.

${ }^{40}$ Em Fijiano (língua austronésia), muitos prefixos e palavras gramaticais aderem fonologicamente ao radical (stem) e participam da contagem alternante dos acentos secundários (cf. Hayes (1995: 143; 145).

${ }^{41}$ O Winnebago (língua Sioux (Siú) ou Dacota) possui, segundo algumas visões (Miner (1979: 25;29), (1981: 341-342), acento de altura. Conforme a literatura disponível, contextos morfológicos diferentes dariam origem a padrões acentuais alternantes também diferentes (binários ou ternários). De um lado, a língua apresentaria uma morfologia em que determinadas formas parecem exibir seu próprio acento (por exemplo, raízes em compostos, em que cada raiz poderia ser considerada como portadora de um acento). De outro lado, determinados afixos (como aqueles referentes à negação e à noção de 'futuro') estariam sujeitos a uma regulação rítmica, isto é, não seriam neutros ao sistema acentual. As questões que a língua Winnebago levanta continuam atuais. Ver também Hayes (1995: 346-364).

${ }^{42}$ A representação fonética dos dados em (2) e também em (3), mais adiante, encontra-se do lado esquerdo, sem os colchetes habitualmente empregados nesse tipo de representação. Do lado direito, entre parênteses, está a representação mais abstrata dos dados, da qual não constam, por ora, informações referentes à camada tonal. Os colchetes nas representações abstratas fazem referência à constituição morfológica das palavras. Nessas últimas representações, o acento linguístico (obtido por regra no âmbito de uma teoria da proeminência) é indicado por um asterisco. A propósito da representação do acento, reveja-se a nota 22 .

${ }^{43}$ Em Tikuna, as propriedades do Tempo não estão codificadas na morfologia verbal (ver Soares (2005)).

${ }^{44}$ Ao longo de nossas investigações, sempre lidamos com uma distinção entre clíticos fonológicos (que não possuem acento primário em relação ao seu hospedeiro) e clíticos gerados sintaticamente (que, como tal, são identificados por critérios sintáticos). Sem haver isomorfismo entre ambos, não há impedimentos para que um clítico sintático passe por um processo de cliticização fonológica, subordinando-se ao acento de seu hospedeiro em determinadas execuções fonéticas.

${ }^{45}$ Em nossa análise (Soares (1992, 1999b, 2000)), clíticos sintáticos não ocupam uma posição argumental em Tikuna, estando co-indexados ao sintagma que os duplica. No interior do sintagma verbal, o elemento pronominal que constitui um clítico sintático se encontra, de modo geral, em distribuição complementar com os morfemas que, no interior do próprio verbo, indicam a existência de um objeto direto - os quais, tanto quanto os clíticos, são dependentes da forma verbal à qual se ligam. Ambos têm como papel indicar que, em um enunciado, há um sintagma interpretável como argumento interno de um verbo. Face aos objetivos do presente artigo, não discutiremos aqui a posição sintática de origem dos clíticos sintáticos em Tikuna, nem o tipo de hospedeiro que, em um quadro de modelo sintático derivacional, os acolherá como sua posição final nessa língua.

${ }^{46}$ Constituem exemplos de bases pronominais em Tikuna as chamadas formas livres dos pronomes pessoais, que apresentam todas um mesmo sufixo categorizador.

${ }^{47}$ Tais verificações têm no seu horizonte a posição de Marantz (2002), segunda a qual a derivação de palavras se dá por fases (ou, em outros termos, por ciclos), havendo linearização a cada anexação de morfema categorizador a uma estrutura. De acordo com essa hipótese, o significado da raiz e sua pronúncia são especificados na primeira anexação de morfema categorizador a uma raiz. Novas anexações de morfema a essa estrutura formada representam contribuição composicional, tendo-se que levar em consideração significado e pronúncia já estabelecidos na fase anterior. Com relação aos morfemas categorizadores em si, são esses considerados como abrigados por núcleos funcionais que, sintaticamente, localizam-se em posição mais alta e à esquerda da raiz ou base acategorial que inclui a própria raiz. Nessa configuração sintática, durante o processo derivacional, a estrutura acategorial (e aquela que essa vier a integrar) será adjungida ao núcleo funcional em questão, em movimento para a esquerda, devido a um traço forte que, possuído por esse núcleo, é desencadeador do movimento sintático que, por sua vez, mantém um elo com o resultado da linearização da sequência final. A representação mais abstrata dos dados a partir de (3) parte da ideia de que a estrutura acategorial (ou aquela que essa integra) já terá sido adjungida à esquerda do núcleo funcional em jogo. Para exemplificação da configuração sintática e do processo derivacional aqui mencionados e voltados para construções em Tikuna, veja-se Soares (2010: 209-213). Com o fim de não sobrecarregar em demasia a representação dos dados, dispensamos o símbolo relativo à raiz $(\sqrt{ })$, utilizado por Marantz.

${ }^{48}$ Ver nota 42. No caso dos dados que apresentam os chamados prefixos verbais, consideramos que as raízes já se encontram aí categorizadas como verbais - fase após a qual se juntariam ao morfema de pessoa. Como não discutiremos aqui se tais Rio de Janeiro | Volume 16 | Número Especial Comemorativo | p. 280-315 | nov. 2020 
marcas de pessoa constituem ou não expressão de concordância, por ora diremos, provisoriamente, que essas integram um sintagma no âmbito verbal (vP).

${ }^{49}$ Dieta, no universo Tikuna, significa recomendação com relação à comida e ao comportamento. Semanticamente, a raiz referente a 'dieta' recobre também a ideia de casulo, de estar coberto. Assim, estar em dieta ou fazer dieta possui relação com o estar como casulo, estar coberto.

${ }^{50}$ Esse dado foi retirado de texto em que se fala da mulher grávida; por essa razão, na tradução livre do dado para o português, aparece a forma pronominal 'ela' (ver nota seguinte).

${ }^{51}$ A marca de pessoa que apresenta traço de familiaridade, intimidade e/ou consideração, isto é, deferência em relação à pessoa de quem se fala, restringe-se, em Tikuna, à terceira pessoa e é não especificada quanto ao gênero (ver Soares (2010: 214; 231, nota 57).

${ }^{52}$ Muitos falantes reconhecem raízes com facilidade, pronunciando-as de forma isolada, sobretudo quando dão explicações sobre sua cultura a alguém de fora. Um suporte empírico adicional provém do fato de que falantes são capazes, espontaneamente, de optar por raízes/bases neutras (isto é, acategoriais) "como entradas de verbete durante o processo de elaboração de dicionário de sua língua e de, no mesmo verbete, ao exemplificar seu uso em uma sentença, manter seu significado nuclear e lançar mão dos recursos morfológicos/sintáticos necessários à sua categorização e consequente utilização sintática como nome ou verbo" (cf. Soares (2010: 210).

${ }^{53}$ No contexto de trabalhos relativamente recentes de autores como Marantz e Harley, $\mathbf{v}$ é uma categoria funcional que, constituída por um feixe de traços, permite a derivação de verbos; do mesmo modo, $\mathbf{n}$ e a são categorias funcionais que, também constituídas por um feixe de traços, permitem a derivação, respectivamente, de nomes e adjetivos.

${ }^{54}$ Ver nota 53.

55 Esse tipo de nominalização (sem prefixo verbal) é encontrável em orações que corresponderiam ao que, em português ou espanhol, por exemplo, seria visto como oração relativa (caso em que uma tradução próxima da construção que abriga a palavra constituída seria algo como ' $\mathrm{X}$ que está no ato de fazer dieta'.

${ }^{56}$ A nominalização de formas verbais plenas (com prefixo verbal) se dá, comumente, em determinadas orações dependentes/subordinadas (as orações complemento, por exemplo).

${ }^{57}$ Pescar com caniço ou anzol.

${ }^{58}$ Nos termos de Harley (2009), teríamos aí um Sintagma Raiz, resultante da concatenação da raiz ao seu complemento, tratado por Harley como um Sintagma Determinante (DP - Determiner Phrase). Para simplificar a apresentação, tratamos o complemento como um nome já categorizado $(\mathrm{N})$ e pluralizado.

${ }^{59}$ Continuam válidas as observações feitas na nota 42 , acrescidas do fato de que se fornecem aqui informações relativas à camada tonal em sua representação inicial, além de sua materialização fonética.

${ }^{60}$ Por questões de espaço, simplificamos aqui a tradução justalinear que, como mostrado anteriormente, é pescar objeto plural [peixes], sendo a construção em causa interpretada como 'na pesca/no ato de pescar objeto plural [peixes]'. Quanto à marca de locativo, presente no mesmo dado, consideramos, conforme nossos trabalhos anteriores sobre a língua em questão, ser a mesma uma posposição, e não um afixo.

${ }^{61}$ A primeira vogal do primeiro sufixo intensificador está sujeita à harmonia vocálica - o que permite discutir sua representação subjacente e o próprio processo de harmonia. Não trataremos desse ponto aqui. Um outro ponto que não será tratado aqui diz respeito à existência ou não de adjetivo na língua e às estratégias empregadas para adjetivar e adverbializar. Assim, sem focalizar aqui a categorização da forma linguística integrada por sufixo(s) intensificador(es) em Tikuna, diremos apenas que esses não alteram a categoria da forma sobre a qual se aplicam.

${ }^{62}$ Nos dados em (7), destacamos, através do negrito, a duração longa devida ao acento rítmico.

${ }^{63}$ Ver Soares (1996)

${ }^{64}$ A propósito, ver também Soares (1992, 1995a, 1995b, 1996, 1998, 1999a, 1999c, 2001)). Soares (1995a) é publicação vinculada a ideias sobre dissimilação tonal e ritmo divulgadas, pela primeira vez, nas Segundas Jornadas de Linguística Aborigen (Buenos Aires, 15 a 18 de novembro de 1994). Da mesma forma, Soares (1998) contém análise sobre subespecificação tonal em Tikuna apresentada, também pela primeira vez, no 16e Congrès des Linguistes (Paris, julho de 1997). Neste último trabalho, a partir de uma linha de análise em conformidade com Clements (1989, ms; 2015), o tom é visto como organizado em componentes tonais, isto é, como um traço hierárquico que organiza um único parâmetro acústico e articulatório (a altura relativa) em séries hierarquicamente organizadas de registros e sub-registros Adotando-se essa visão, a variável $\alpha$ (comum em trabalhos de fonologia gerativa) pode ser utilizada para indicar um dado componente tonal. Em razão de as representações de base serem vistas em Soares (1998) como subespecificadas, o tom Alto (A), possui, em sua representação subjacente na camada tonal, somente uma primeira linha / fileira ('row'), nessa se fazendo presente um componente tonal alto (a); do mesmo modo, a representação de base do tom Baixo é constituída de apenas uma primeira linha / fileira ('row') preenchida por um componente tonal baixo (b). Quanto ao tom médio, suas especificações estariam ausentes em uma representação de base. Concebido como default, fruto de inserção, em um modelo derivacional, e aparentemente sem atividade fonológica, o tom Médio (M) possuiria duas linhas / fileiras ('rows'), cada uma com seu respectivo componente tonal - alto (a) e baixo (b). E, mais do que isso, poderia ser visto como não especificado, isto é, como ausente, de modo Rermanente, das representacões fonológicas. Ainda em Soares (1998), por efeito de diferenciações estabelecidas na realização Celebrando mais de 50 anos do Programa de Pós-Graduação em Linguística da UFRJ e do percurso da Professora Emérita Miriam Lemle 
dos tons, ao lado de dissimilações tonais, podem ocorrer ainda, foneticamente: a) elevação do tom Alto ( $\overline{\mathrm{A}}$ ); b) abaixamento do tom Baixo $(\overline{\mathrm{B}})$. Esses dois processos podem ser concebidos como resultantes da inserção não obrigatória de um componente alto ou baixo na linha/fileira 2 ('row' 2).de um tom Alto (A) ou Baixo (b) subjacentes. Soares (1998) também aponta para efeitos de margem no domínio da palavra morfológica, isto é, elevação de tom Alto e abaixamento de tom Baixo estariam ligados a uma posição morfologicamente definida (margem da palavra). Os processos de dissimilação tonal, elevação e abaixamento de tom convivem com processos de propagação (espraiamento) tonal. De acordo com Soares (1998), esses últimos sustentam a representação tonal de base proposta, são não obrigatórios, bidirecionados e têm lugar por sobre uma extensão silábica mínima (duas sílabas, uma como alvo e a outra como fonte).Como os processos de propagação dizem respeito unicamente às representações finais, Soares (1998) os vê como legitimados de modo indireto.Seu domínio é a palavra morfológica e seu legitimador indireto é a vogal não especificada do ponto de vista tonal, sendo a adjacência silábica necessária aos processos de propagação tonal.

${ }^{65}$ Em trabalhos anteriores, ao lidarmos com as realizações fonéticas dos tons em Tikuna (Ticuna), referimo-nos à mais alta das alturas fonéticas como simplesmente alta, reservando o termo meio-alta para fazer referência à segunda altura que, sendo ainda alta, estaria um grau abaixo da mais alta. Fizemos o mesmo em relação às alturas situadas na esfera do baixo, utilizando o termos meio-baixa, ao referirmo-nos à segunda altura que, sendo baixa, estaria um grau acima de uma outra também baixa, por sua vez vista como baixa. Posteriormente, devido à vantagem de uma conexão maior entre a análise fonológica do tom e suas realizações fonéticas na língua estudada, optamos por fazer referência à mais alta das alturas fonéticas como alta elevada (extra hight pitch) e à segunda altura alta, situada um grau abaixo da mais alta, como alta (hight pitch). Da mesma forma, passamos a adotar o termo baixa (low pitch) para nos referir a uma altura de voz baixa situada um grau acima de outra também baixa, por sua vez tratada como baixa abaixada (extra low pitch).

${ }^{66}$ Outros exemplos de trissílabos em que a primeira sílaba porta tom em nível baixo, terminando as sílabas finais por portar tom médio: /o?kuna/ ' clã'; /õt Jana/ 'bebê' (cf. Soares (2001:13).

${ }^{67}$ Rever nota 64.

${ }^{68}$ Cf. Soares (1995a: 150). Ver também Soares (1996).

${ }^{69}$ A formalização em (12) não fornece indicações sobre a direção da dissimilação.

${ }^{70}$ Rever nota 64. Em Soares (1998), o tom é visto como organizado em componentes tonais. Adotando-se essa visão, a variável $\alpha$ (comum em trabalhos de fonologia gerativa) pode ser utilizada para indicar um dado componente tonal, como ocorre na formalização em (13). Ver também Soares e Damulakis (2007:235).

${ }^{71}$ Lembramos que o pé métrico delimitado, em seu formato pleno, possui núcleo localizado em uma de suas margens (esquerda ou direita) e um lado dominado, integrado por uma sílaba ou mora (rever o início da seção 1 em II). No caso Tikuna, o pé métrico apresenta núcleo em sua margem esquerda, ou seja, é um pé trocaico.

${ }^{72}$ Sobre análise local fraca e análise local forte, rever seção 1.1 em 1.

${ }^{73}$ Ver Soares (1992, volume II, p. 593).

${ }^{74} \mathrm{O}$ dado fonético em (16) também apresenta um processo de queda vocálica que envolve dois segmentos vocálicos idênticos, porém diferenciados quanto ao que seria tonicidade, por efeito de sua posição no interior de seus respectivos pés métricos: a última vogal da raiz e a vogal que abre o primeiro sufixo.

${ }^{75}$ Ver nota 71.

${ }^{76}$ A diferença entre operação de grade referente apenas à camada acentual e operação de grade devida a uma regra rítmica de nível baixo foi estabelecida em Soares (1999: 237-238).

${ }^{77}$ Ver Soares (1992, vol. II, p. 597).

${ }^{78}$ Veja-se a proposta de Baker (1988), que pode ser trazida para um momento mais atual da teoria gerativa. Primeiro, através da ideia de que núcleos funcionais categorizam raízes e, com isso, passam a contê-las. Segundo, por meio do mecanismo conhecido como conflation (fusão), que, proposto por Hale e Keyser (2002:60-88), é um movimento de núcleo que se dá por razões fonológicas: a matriz fonológica de um constituinte é concatenada a um núcleo irmão defectivo. Com isso, o mecanismo conflation torna-se parte, de alguma forma, da operação Merge (Concatenar), evitando os problemas trazidos pela concepção sintática de movimento de núcleo para núcleo - problemas esses que surgem no âmbito de uma teoria sintática mais atual e diferente daquela em que Baker (1988) fez a sua proposta. Ver a propósito Harley (2003).

${ }^{79}$ Cf. Harley (2008: 2; 7-8).

${ }^{80}$ Subentende-se aqui que 'as costas estão vermelhas' devido ao uso do urucum.

${ }^{81}$ Reler a nota 29. 